\title{
Multi-agent System for Management of Data from Electrical Smart Meters
}

\author{
Yazid Hambally Yacouba \\ Training and Research Unit for Mathematics and Computer Science, Félix Houphouet Boigny University, Côte d'Ivoire \\ E-mail: yazid.hambally@gmail.com
}

\section{Amadou Diabagaté}

Training and Research Unit for Mathematics and Computer Science, Félix Houphouet Boigny University, Côte d'Ivoire E-mail: ahmadou.diabagate@gmail.com

\author{
Abdou Maiga \\ Training and Research Unit for Mathematics and Computer Science, Félix Houphouet Boigny University, Côte d'Ivoire \\ E-mail: maiga.abdou@gmail.com \\ Adama Coulibaly \\ Training and Research Unit for Mathematics and Computer Science, Félix Houphouet Boigny University, Côte d'Ivoire \\ E-mail: couliba@yahoo.fr
}

Received: 12 June 2020; Accepted: 06 September 2020; Published: 08 February 2021

\begin{abstract}
The smart meter can process sensor data in a residential grid. These sensors transmit different parameters or measurement data (index, power, temperature, fluctuation of voltage and electricity, etc.) to the smart meter. All of these measurement data can come in different ways at the smart meter. The sensors transmit each measurement data to the smart meter. In addition, the collection of this data to a central system is a significant concern to ensure data integrity and protect the privacy of residents. The complexity of these data management also lies in their volume, frequency, and scheduling. This work presents a scheduling and a collection mechanism in private power consumption data between both sensors and smart meters on one hand and between smart meters and the central data collection system on other hand. We have found several approaches to intelligent meter data management in scientific researches. We propose another approach in response to this concern for the scheduling and collection of measurement data to a central system from residential areas of sensors' network connected to smart meters. This work is also an example of a link between data collection and data scheduling in intelligent information management, transmission, and protection. We also propose a modeling of the measurement objects of smart grid and highlight the changes made to these objects throughout the process of data processing. It should be noted that this smart grid system consists of three main active systems namely sensors, smart meters and central system. In addition to these three systems, there are other systems that communicate with the smart meters and the central system. We have identified three implementation models for the smart metering system. We also present an intelligent architecture based on multi-agent systems for the smart grid. Most current electricity management systems are not adapted to the new challenges imposed by social and economic development in Africa. The objectives of this study are to initiate the design of a smart grid system for the management of electricity data.
\end{abstract}

Index Terms: Sensor, residential smart grid, smart meter, measurement data, collection mechanism, power consumption data, central data collection system, multi-agent system.

\section{Introduction}

There are several data management solutions for intelligent electrical systems, but the design and implementation of these solutions remain a well-kept secret by most of the power companies in charge of managing this data. This study is an intrusion into the design of these systems in order to make them more affordable.

The main objective of this study is to present an electricity management system able of collecting electricity consumption data, ordering and identifying them from their initial sources. The main expectations are the ability of the multi-agent system to facilitate data processing and to guide consumers in reducing their electricity consumption. The study does not address the performance of the proposed system but rather focuses on the design of the upstream phases facilitating the processing of electricity data. 
The mechanism for collecting data from the sensors to the central system is to feed the primary database and other databases of the actors of the electricity value chain from the customers' system. This central database initially smaller can nevertheless quickly reach a significant size due to the production of other additional data by the central system.

More generally, we focused this work on certain researches including articles $[1,2]$ that demonstrate the value of collecting data from smart meters in classifying electricity consumers in order to provide them with quality service. The interests of these papers have motivated the need to deepen the analysis of ways and means to develop an electricity management system based on smart sensors and smart meters. Our work will then consist of the proposal of a multiagent system making it possible to expose the concerns related to the management of electricity data accessible from smart meters. This work should facilitate the centralization of electricity data and the implementation of data analysis with the aim of seeking the results favoring, among other things, the categorization of users for service offers adapted to their needs [2]. The article [2], which results will not be treated within the framework of this present paper aroused a major interest. This interest will nevertheless make it possible to consider a publication that is interested in or will specify the criteria for classifying customers while determining data that allow such categorization.

Fadi Shrouf and Giovanni Miragliotta show the importance of integrating real-time energy data into production management [1]. The change in user behavior, particularly with the awareness of ecological issues, has also led decision-makers to prioritize green manufacturing. This is how smart sensors and meters have emerged in industry to drive green electricity consumption through the Internet of Things paradigm. This study also examines the critical role of real-time data collection for analysis and improving energy-sensitive decision-making.

Likewise, Alexander Martin Tureczek and Per Sieverts Nielsen provide insight into the classification of consumers based on smart meter data through this literature review [2].

We aim to highlight the following points throughout this research work:

- Multi-agent presentation of the system;

- Specific presentation for each agent and interactions between the different agents;

- The importance and contribution of smart meters;

- Scheduling and collection of measurement data;

- Presentation of architecture of the central system.

Smart grids in fact provides an efficient decision support when data collection and analysis are done in real time for the entire power system. Sensors and smart meters become necessary for an effective smart grid operation [3]. Madeline Martinez-Pabon and al. propose a limited memory algorithm for the limited problems related to the intelligent home energy management [4]. Markus Mäsker and al. shows the impact of the change in energy prices in smart grids and the interest of this study for data centers [5]. Ilze Laicane, Dagnija Blumberga, Andra Blumberga, Marika Rosa highlight the importance of information transmitted by smart meters for energy-saving advice and the contribution of this information in reducing peak load [6]. Joshua D. Rhodes and al. present the experimental and data collection methods for a large-scale smart grid deployment in Austin, Texas, and provide results based on these [7].

The management and analysis of data from conventional meters were already possible for production data after the manual collection phase [8]. This approach is however insufficient for the development of an efficient energy policy and the optimization of production. The processing and exchange of these data between the different actors go through their structuring. Indeed, the adoption of standard formats will promote the interoperability of electrical systems, the reuse, the analysis and the aggregation of data. The exchange of data will make a better profit by homogenizing their treatments and producing real benefit $[9,10]$.

The data collection mechanism will help to:

- Quickly identify faults more efficiently on the electrical network;

- Detect fraud or fraud attempts;

- Create a data analysis center for energy saving and predictive analysis purposes;

- Transfer the data to the concerned actors;

- $\quad$ Set up tools for analyzing and visualizing data from electric meters;

- Facilitate the balancing of consumption and production according to the demand and the constraints of electricity production and supply.

This work can also be used to collect a set of information including the state of electrical energy consumed by an electric vehicle, a photovoltaic system or stored by a storage battery [11].

It is certain that real-time access to electricity data will encourage the development of new opportunities (crossreferencing data and modern energy services to consumers) $[12,13]$. 


\section{Literature Review}

Analysis of the literature on smart grids related to this paper highlight several areas of interest. We are going to present some centers of interest of the present work, which are:

- The studies of the application of algorithms for calculating forecasts to economic issues;

- The different opportunities and technologies related to electrical smart grid infrastructures;

- The security of these systems that constitutes an issue of national sovereignty;

- The management of data from the electrical intelligent systems.

We will also cite throughout this work, various works related to our concerns.

Among the studies relating to forecasting models, we will cite [14, 15]. [14] is a critical review of the forecasting models for renewable energies and electricity applied as an energy-planning tool. This study of forecasting models show spatial and temporal approaches applicable to policy and planning objectives for the management of data warehouses with higher forecasts thanks to the combination of different models. Rabiya Khalid and al. highlight the role of forecasting using data warehouses in modifying electricity consumption patterns from the original price model and in responding to electricity prices and incentives [15]. This work proposes a model that predicts electricity consumption demands and prices by using several input variables.

There are also many studies on opportunities and technologies related to smart grids. Géremi Gilson Dranka and Paula Ferreira present a billing system that does not meet user expectations due to low deployment of storage technologies [16]. The modernization of the electricity system through the implementation of an intelligent electricity system is a global trend from which Brazil cannot escape. This study reports on the state of the electrical system in Brazil, which is very close to that of Africa. In Brazil as in Africa, the current electrical system requires a change for new perspectives. Gerwin Evers and Maryse M. H. Chappin show the level of knowledge sharing on intelligent electrical networks and presents four levels of classification of this knowledge: intra-organizational, intra-project, interproject and project-external knowledge sharing [17]. M. Ourahou and al. realise an overview of the opportunities for smart grid to reduce pollution with renewable energy [18]. This study focuses on the integration of energies in smart grids and on control measures that ensure a good continuity of electricity supply. [19] is a survey of different enabling technologies used in smart grids as well as future opportunities and perspectives. This study is a guide to the deployment of infrastructures in smart grids.

The security of intelligent electrical networks is one of the concerns raised by the critical nature of the issues surrounding this new technological trend and several studies exist on this subject. The vulnerability of smart grid security is one of the consequences of the technological and economic revolution brought about by the modernization of electricity grids [20]. Sensors have an essential role in smart grids by allowing the detection of failures, reduction of damage, adjustment of parameters [21]. Smart grids are very critical and exposed to cyber security attacks. The communications systems of these networks can be subject to threats to national security and integrity [22]. The vulnerabilities to which smart grids are subject can disrupt public order and cause significant economic loss.

The design of data management models for intelligent electrical systems is a research concern. We present some studies on a subject, which also motivated our research work. This paper [23] shows the big research interest in the management, analysis and processing of data from smart meters, particularly with the advent of the Internet of Things (IoT) devices, including smart meters and sensors in the smart grid. This study also shows the importance of high computational capacity for the performance of processing large data from smart meters. Bassirou Diène and al. present data management based on the concept of the Internet of Things [24]. It also highlights the merits of designing data management systems with the Internet of Things paradigm, particularly in middleware or architecture-oriented systems. [25] explains the difficult task and challenge of collecting abundant data from users' electricity consumption patterns for utility companies. This article discusses a method of predicting the consumption of each user within an hour in order to reduce the cost of electricity use by end users. We also faced with the problem of data collection, which constitutes an important part of our paper. This article [26] is an attempt to adapt capability maturity models (CMMs) to big data standards for processing data from smart grids. There are also several approaches to scheduling data from smart grids $[27,28]$.

Knowledge about the design of intelligent electrical systems remains largely a black box. It is in particular the difficulties linked to this lack of information, which motivated our research towards the proposal of a multi-agent system presenting the various components of the intelligent electrical system, as well as answers for scheduling, collection and data processing. 


\section{Problematic}

\subsection{Application context}

Energy is one of the biggest challenges of the African continent and one of the main pillars of its economic growth. Population growth and urbanization exploding must go hand in hand with energy production that meets growing demand. It is therefore necessary to respond to the challenges linked to the strengthening of the energy supply and the quality of electrical energy distribution. These objectives call for an energy mix policy for the diversification of production sources [29].

The production and management of energy involve research projects on ways and means to fill the energy deficit and provide adequate solutions to the implementation of an approach that would use technological advances [30]. More and more investments are underway or planned for the production of energy for the electrification of the African continent. However, the modernization of electricity networks and its management must follow suit to bring intelligence to the traditional process of the functioning of the electricity market. Indeed, the companies supplying electrical energy sometimes record significant financial losses due to piracy, notably rigged meters and arrangements with mafia agents. Subscribers pay for the financial deficit caused by small and large pirates and in some cases states, electricity suppliers and subscribers share the losses.

Natural gas, geothermal, solar, wind, coal, nuclear, biomass are all sources of energy usable for electrification. Ways must, therefore be found to use all these forms of energy for the benefit of African people. The development of agriculture, animal husbandry, access to education, and health centers requires a profitable and an efficient supply of electricity. Several initiatives are already underway in certain developed countries and, through this research work, we wish to analyze the advances already recorded to develop local technologies and to master transfer by developing or at least laying the foundations for the design and implementation of a computer system for African countries. The automation of operations resulting from the intersection of energy production, supply and billing activities will be the key to the implementation of such a computerized energy system.

\subsection{Issues}

To date, most African utilities operate with traditional metering systems based on metering and set of meters, followed by manual data collection and most often physical distribution of bills [31].

The insufficiency of this mechanism is intrinsically linked to the mechanical character of the treatment of each stage of the energy value chain. The response times of electricity companies are sometimes long, and customers receive overdue invoices in some cases. In addition, the difficulties of collecting consumption data because of the inaccessibility or the difficulty of locating electromechanical meters leads to the editing of invoices based on estimates, which are sometimes contested because they do not conform to reality. It is therefore urgent to set up a computer system capable of overcoming the difficulties encountered by using a process based on advanced meters. The new method should enable automation of data retrieval, billing and remote modification of metering parameters [32]. The advanced metering system must also allow for the emergence of new service offerings [33].

The new energy system must centralize consumer data and facilitate steering and active participation in optimization and reduction of electricity bills. Customers must be able to tailor vendor offerings at any time according to their needs and the technical constraints of the network and the services available.

This new system must be able to provide all stakeholders with access to data analysis. It must also make it possible to carry out remote operations (reading, parameterization, and distant cuts) [34].

The implementation of an advanced energy information system will depend on the use of advances in Information and Communication Technologies [35]. Thus, we propose to study the implementation of a smart grid information system.

We plan to carry out studies that will help to understand and identify the problems caused by the design of a metering system. This research work aims at facilitating the realization of computer systems that will contribute to energy efficiency and the reduction of electricity consumption. We want to allow an awareness that breaks with habits more and more inadequate to the needs of consumers to embrace the development of tools that respond to realities. The information system based on the use of smart meters is one of solutions to Africa's energy problems, mainly through the integration of renewable energies and the development of responsible consumption [36]. Current electrical installations are not very adapted to new technological challenges that require the inclusion of intelligent hardware and software commonly known as the "smart grid" network. In addition, the Africans must design and realize their energy solutions as the financial cost for the transition to the smart grid is essential especially on a continent where the concerns of the populations are numerous [34].

\subsection{Interest of smart meters}

Smart meters aim to modify bad usage behavior and anticipate the management of peak consumption.

Advanced meters facilitate the integration of renewable energy for electrification. The management of these 
intermittent energies as solar requires taking into account their particularity. They can display the consumption load curve and indicate the anomalies observed in the automatic process of electricity consumption. The smart meters therefore make it possible to analyze the consumption of energy delivered by the distributor. In addition, knowing consumers' needs makes it possible to adjust distribution and manage demand so as to reduce energy losses and power outages. Advanced meters remain one of the best alternatives for the implementation of an efficient electricity market. The main contribution of smart meters compared to traditional meters is the possibility for individual consumption control and for distribution network managers to plan their investments. Mobile phones, tablets, computers and other specialized equipment can serve as remote interfaces for relaying metering information and formatting it as a basis for decision-making by users.

A platform accessible by all stakeholders can centralize customer consumption data, which will guarantee the transparency of consumption statements and the strengthening of the relationship of trust. The quality of the data collected and its accessibility will facilitate new proposals for offers to customers and boost fair competition in the energy supply and sale market. The deployment of advanced meters will result in the possibility of programmed shutdown, re-establishment of access, improving the quality of data billing and reduction of technical losses due to the elimination of electromechanical meters.

Indeed, smart meters can be used to study the behaviors and habits of individuals. In addition, the qualifier "intelligent" excessively assigned to meters fuels the fear of losing autonomy on a device that will tend to decide for users. This intelligence of smart meters can be interpreted as the ability of suppliers to automatically manage customers. They can also contribute to the improvement of daily users' life, especially those requiring flexibility in administrative procedures for the management of their electricity contracts.

\section{Multi-agent System Proposed}

\subsection{Requirements of the multi-agent system}

The sustainable development of advanced electrical metering systems requires convergence and synergy between the actors in electricity, electronics, telecommunications and IT. This development is also based on the will of public authorities, private companies and consumers.

The smart meter is a subject that receives a lot of attention and raises many questions. Several projects are already under consideration around the world.

The main objectives identified for the deployment of smart meters in Africa are:

- The fight against fraud and theft of energy;

- The statement of actual consumption and dispatch of invoices on time;

- The electrification of urban and rural areas using renewable energy sources, particularly solar.

Africa's solar potential is a source of motivation for the use of smart meters and the development of a system that will allow remote management of all advanced meters' functions. The major challenge, however, lies in the implementation of an information system capable of meeting the expected objectives, especially in a context where cost reduction is sometimes an important issue.

It is necessary to evaluate the following elements before a decision of generalization or experimentation:

- Technical feasibility analysis;

- Cost and benefit analysis;

- Environmental and social impact.

Smart meters must present an interface whose functions are understandable at a glance. The smart meter must also be a responsible means for an essential trend towards good management of electricity consumption. Above all, it must contribute to improving and changing household habits. The choice of which smart meter device to deploy must be based on the completeness of its functions, intuitiveness and guarantees for other innovations.

The main costs to consider are awareness, investment, depreciation, operation, communication and operational process.

Once the opportunity has been proven, the decision to deploy smart metering systems must be taken jointly with all the actors (regulatory authority, consumers, network managers, suppliers).

The installation of smart meters is not a prerequisite for the deployment of a smart grid.

The main and common requirements identified for the deployment of smart metering systems are:

- Offers of less expensive tariff formulas based on an exact statement of consumption;

- Development of a communicating distribution network;

- Access to consumption data by customers, suppliers, distributors and electricity consumers; 
- Reduction of fraud and unauthorized access to control smart meters;

- Standardization of smart meters' interfaces and communication with equipment based on open standards.

The specific requirements of our multi-agent system concern the continuity of data collection from all sources of electricity consumption and the possibility for the system to resume collection correctly in the event of a breakdown. Likewise, the requirements of our multi-agent system are intrinsically linked to those of the monitoring and integrity of the electricity supply. Protecting the exchange of information between smart meters and the central data storage environment is also one of the main security requirements for ensuring data integrity [37].

\subsection{General presentation of the multi-agent system}

In the system, agents are smart meters, smart sensors and the central system that interact with each other through the transmission of measurement data. The model of the multi-agent system is defined as follows:

The smart meter agents collect the measurement data thanks to the smart sensor agents and transmit this consumption data to the environment. Smart meter agents do not cooperate directly with each other and each have a unique identity in the environment;

The environment is made up of the central system to which all the smart meter agents transmit their measurement data for processing.

The measurement data collected by each smart meter agent is ordered to facilitate its processing and to produce understandable and visible results on the environment. These results provide an understanding of the agent's behavior and its impact on the environment and within the organization. The large number of smart meter agents in the organization and the large amount of data produced by each agent militates in the implementation of an automated processing of collection and scheduling of the measurement data.

The environment of the multi-agent system receives measurement objects. These objects then evolve while remaining attached to their source of origin "smart meter". All the changes made to measurement objects in the environment are intended to facilitate their processing. The processing approached consists in the collection of measurement data by the agent, in the transfer and in the scheduling of this measurement data within the central system. The agents of the system are reactive by responding to requests from the environment for the transfer of measurement data. It is also possible to transfer part of the environmental processing within the smart meter agent, which would make it smart by enabling it to acquire autonomy, proactivity and adaptability. However, we opted for a centralization of data in order to create an inclusive environment, which would provide each smart meter agent with sufficient intelligence based on collective intelligence. This intelligence could also be shared and analyzed to extract new information. The agents of the conceptual model are reactive, non-proactive and non-social.

Our multi-agent system must be autonomous and reactive. The agents and the environment must interact independently of any outside intervention. The agents must also perceive any change in the environment and react in a timely manner to these changes [38].

\subsection{Different agents of the system}

To highlight the different components of the smart grid, we chose to expand it into a multi-agent system. This approach will allow us to present the various agents and their interactions as well as sensors, smart meters, central system and other active components of the environment of the smart grid. This modeling will take advantage of all the advantages of a multi-agent system including:

- Modularity thanks to information sharing between agents ;

- Reliability thanks to redundancy;

- The speed of execution thanks to the parallelism of execution of the tasks performed by the different agents ;

- The ease of maintenance when adding a new component within the smart grid.

The different agents of the system are as follows: 
Table 1. List of the agents in the system

\begin{tabular}{|c|c|}
\hline Agent name & Tasks \\
\hline Sensor Agent (SA) & Sensor Management \\
\hline Smart Meter Agent (SMA) & Data receiving and transmission \\
\hline \multirow{3}{*}{$\begin{array}{c}\text { Central System Electricity Management } \\
\text { Agent (CSEMA) }\end{array}$} & Central System Data Processing Under Agent (CSDPA) \\
\cline { 2 - 2 } & Central System Data Exchange Under Agent (CSDEA) \\
\cline { 2 - 2 } & Central System Data Lookup Under Agent (CSDLA) \\
\cline { 2 - 2 } Electricity Customer Agent (ECA) & Electricity supply management and electricity consumption consulting \\
\hline Electricity Distributor Agent (EDA) & Electricity Distribution Management Under Agent (EDMA) \\
\hline $\begin{array}{c}\text { Electricity Transmission Networks } \\
\text { Manager Agent (ETNMA) }\end{array}$ & Electricity Transmission Management Under Agent (ETMA) \\
\hline Electricity Producer Agent (EPA) & Production Management Under Agent (PMA) \\
\hline
\end{tabular}

\subsection{Representation of the multi-agent system of the electricity value chain}

This presentation highlights the flow of exchanges between the different agents of the system [39, 40]. The exchanges mainly take place around the central electricity management system, which implements the different treatments thanks to its sub-agents. The intelligent sensor agent that interacts directly with Smart Metering Agents is the only agent in the environment that does not interact directly with the central system. In addition, other agents in the system environment communicate either directly or through the central system.

Figure 1 highlights the simple agents, the composite agents and presents the links between all these agents. The design of a modular system composed of autonomous and intelligent software entities interacting with each other makes it possible to take advantages of a multi-agent system (reliability, speed, parallelism, scalability). Agents are the set of system tasks involved in managing electricity data from smart meters. Below is the list of agents involved in the multiagent system.

Table 2. Designation of agent tasks in the multi-agent system

\begin{tabular}{|c|c|c|}
\hline Designation of agent & Tasks & \\
\hline Sensor Agent (SA) & $\begin{array}{l}\Rightarrow \\
\Rightarrow \\
\Rightarrow\end{array}$ & $\begin{array}{l}\text { Activating the sensor; } \\
\text { Disabling the sensor; } \\
\text { Transmitting sensor data to } \\
\text { smart meter. }\end{array}$ \\
\hline Smart Meter Agent (SMA) & $\begin{array}{l}\Rightarrow \\
\Rightarrow\end{array}$ & $\begin{array}{l}\text { Receipt of smart meter data ; } \\
\text { Data exchange with the smart } \\
\text { meter. }\end{array}$ \\
\hline $\begin{array}{c}\text { Central System Agent for Electricity } \\
\text { Management (CSEMA) }\end{array}$ & $\begin{array}{l}\Rightarrow \\
\Rightarrow \\
\Rightarrow \\
\Rightarrow\end{array}$ & $\begin{array}{l}\text { Data processing of the central } \\
\text { system; } \\
\text { Central System Data Analysis; } \\
\text { Data exchange with the central } \\
\text { system; } \\
\text { Central system data } \\
\text { consultation. }\end{array}$ \\
\hline Electricity Customer Agent (ECA) & $\begin{array}{l}\Rightarrow \\
\Rightarrow \\
\Rightarrow\end{array}$ & $\begin{array}{l}\text { Management of the customer's } \\
\text { power supply; } \\
\text { Consultation of the state of } \\
\text { electricity consumption; } \\
\text { Exchange of data with the } \\
\text { customer. }\end{array}$ \\
\hline Electricity Distributor Agent (EDA) & $\begin{array}{l}\Rightarrow \\
\Rightarrow\end{array}$ & $\begin{array}{l}\text { Management of electricity } \\
\text { distribution; } \\
\text { Data exchange with the } \\
\text { electricity distributor. }\end{array}$ \\
\hline $\begin{array}{l}\text { Electricity Transmission Networks } \\
\text { Manager Agent (ETNMA) }\end{array}$ & $\Rightarrow$ & $\begin{array}{l}\text { Electricity transmission } \\
\text { management; } \\
\text { Data exchange with the } \\
\text { electricity transmitter. }\end{array}$ \\
\hline Electricity Producer Agent (EPA) & $\begin{array}{l}\Rightarrow \\
\Rightarrow\end{array}$ & $\begin{array}{l}\text { Management of electricity } \\
\text { production; } \\
\text { Data exchange with the } \\
\text { electricity producer. }\end{array}$ \\
\hline
\end{tabular}




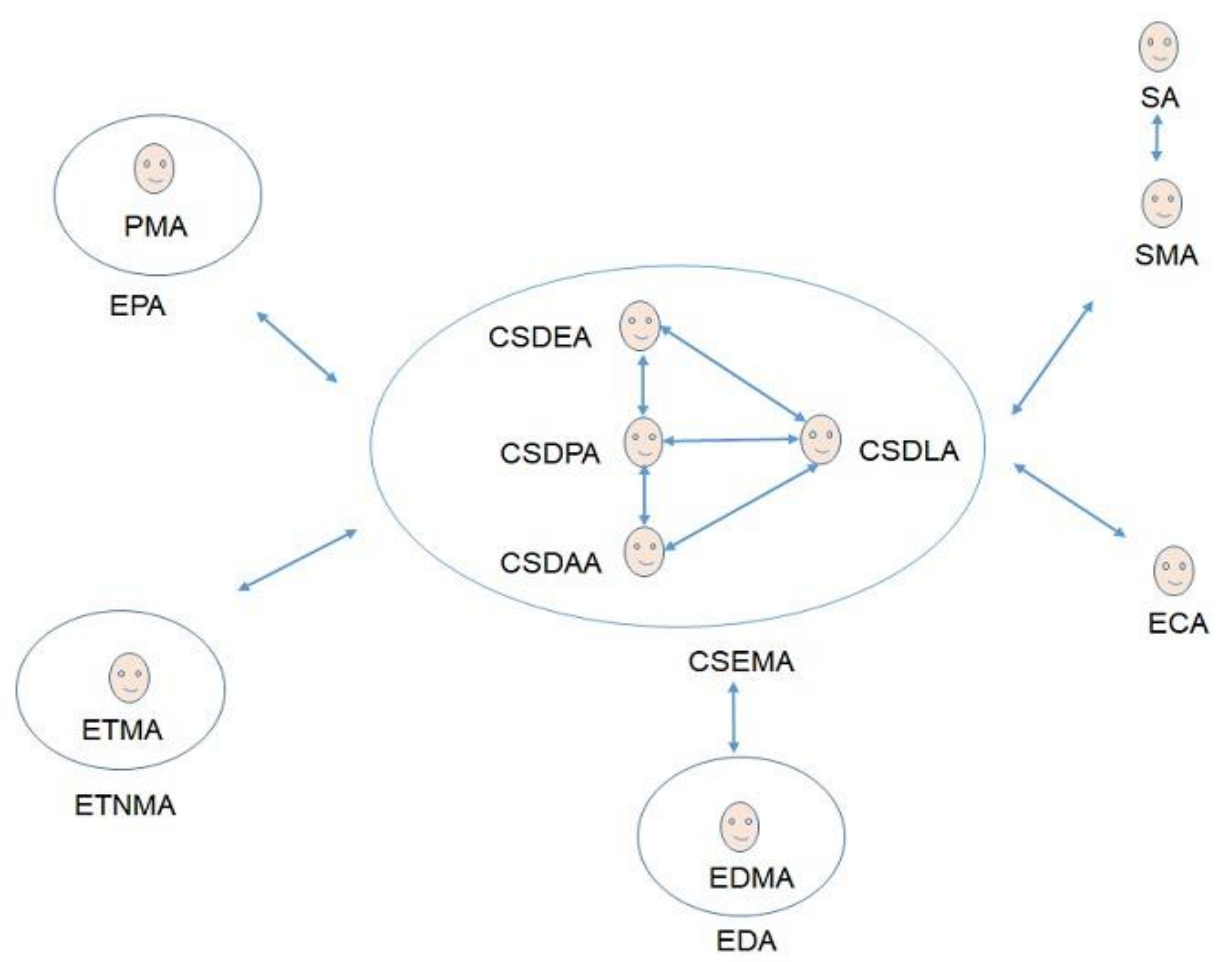

Fig.1. Multi-agent system of the electricity value chain

\subsection{Multi-agent architecture by detail}

This architecture highlights all the agents of the multi-agent system. It makes it possible to distinguish the agents in contact with the external environment without however being precise on the other agents of the system. It also has the merit of giving an overview of all interactions between agents [41].

With regard to Figure 2, it provides an exploded view of all the agents, which interact in communication with other actors in the electricity value chain.

This section highlights the visibility of interactions between the agents of the system and its environment. It shows the sharing of information (consultation and insertion) between all actors in the electricity value chain. Below is the description of the interactions:

- Consumers through the different types of electricity use (lighting, air conditioning, electrical outlets) act on sensors, which assess the electricity consumption generated and transmit the consumption data to the smart meter to which the sensors are associates. Consumers are therefore users responsible of the electricity consumption recorded by smart meters;

- Customers can consult the evolution of electricity consumption from their smart meters at any time. They then have the opportunity to understand the points of reduction of their consumption;

- Operators in charge of data collection interactively access data stored in smart meters. They can also make new settings or provide remote assistance in the event of a malfunction;

- Distributors, suppliers and transmission network operators manually enter data or integrate this data into the central system from an import file or automatically.

- The data consulted can be obtained in the form of an output report which is a file containing all the information relating to the requests applied to the central system;

- All the entities can communicate with each other through the central agent of the system allowing consultation and insertion of data into the multi-agent system;

- All actors in the electricity value chain have access only to data for which access rights have been granted to them. 


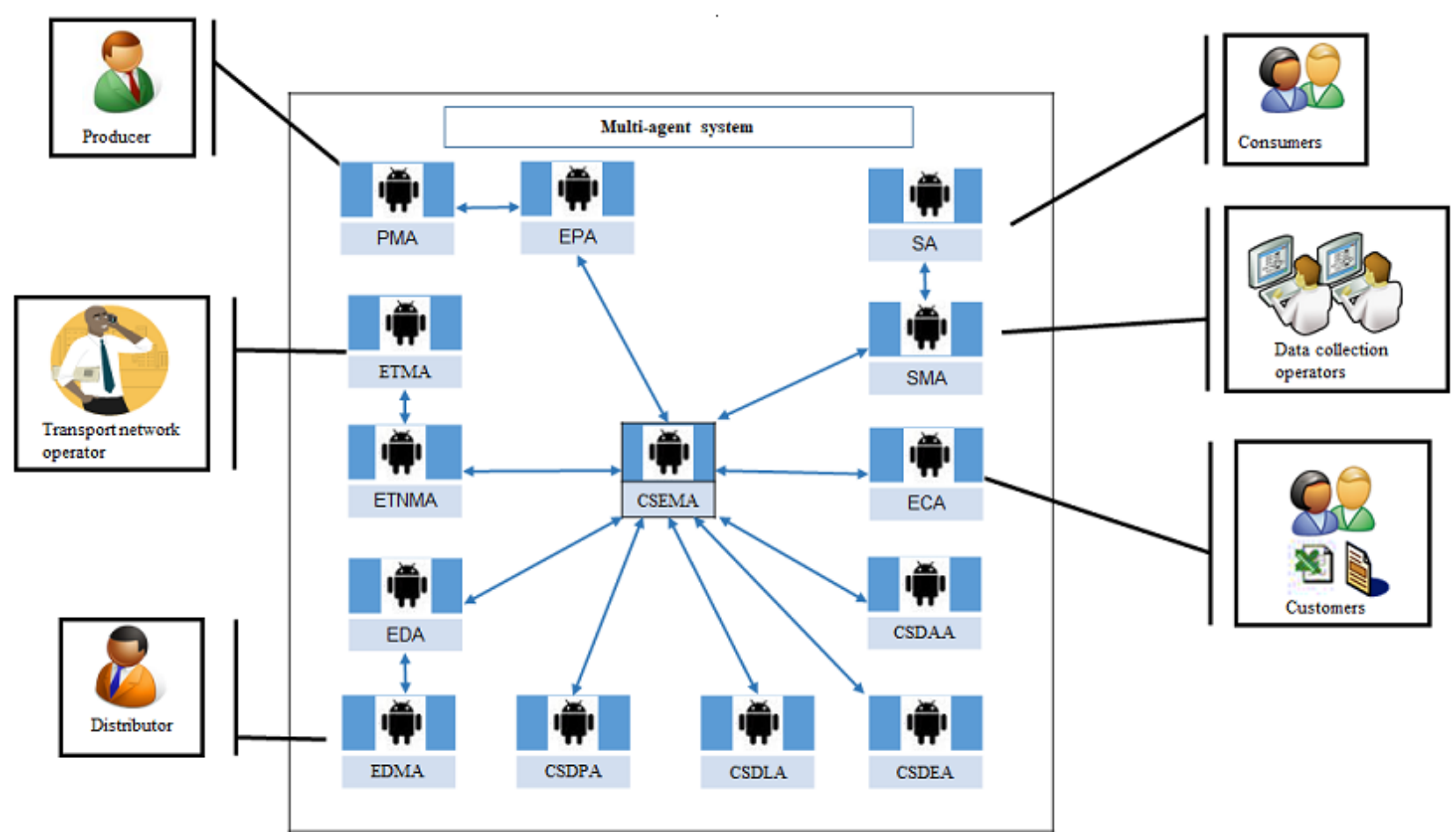

Fig.2. Detailed multi-agent architecture

\subsection{Multi-agent architecture per layer}

This architecture highlights the different layers of the proposed multi-agent system:

- HMI layer: it closes all the agents allowing interaction with the system. The agents in this layer allow you to interact with the system according to the user's profile. Indeed, access to data is inherent to the type of user. Among the various users of the system, we can cite the producer, the transmission network operator, the distributor, the consumers, the operators in charge of managing data collection and the customers. Each type of user corresponds to a category of accessible data in order to guarantee the proper functioning of the system. The purpose of this system is to participate in the proper regulation of the electrical energy sector ;

- Business layer: it brings together the agents in charge of data processing. Each actor in the electricity value chain has a specific agent responsible for processing the data. It is this layer which is responsible for structuring data into business objects or for maintaining them in the form of raw data;

- Semantic layer: it constitutes the framework for data analysis thanks to specific treatments applied to data often through scheduled tasks ;

- Physical layer: it constitutes the data warehouse and contains three types of data, which are raw data, structured data and analysis data. 


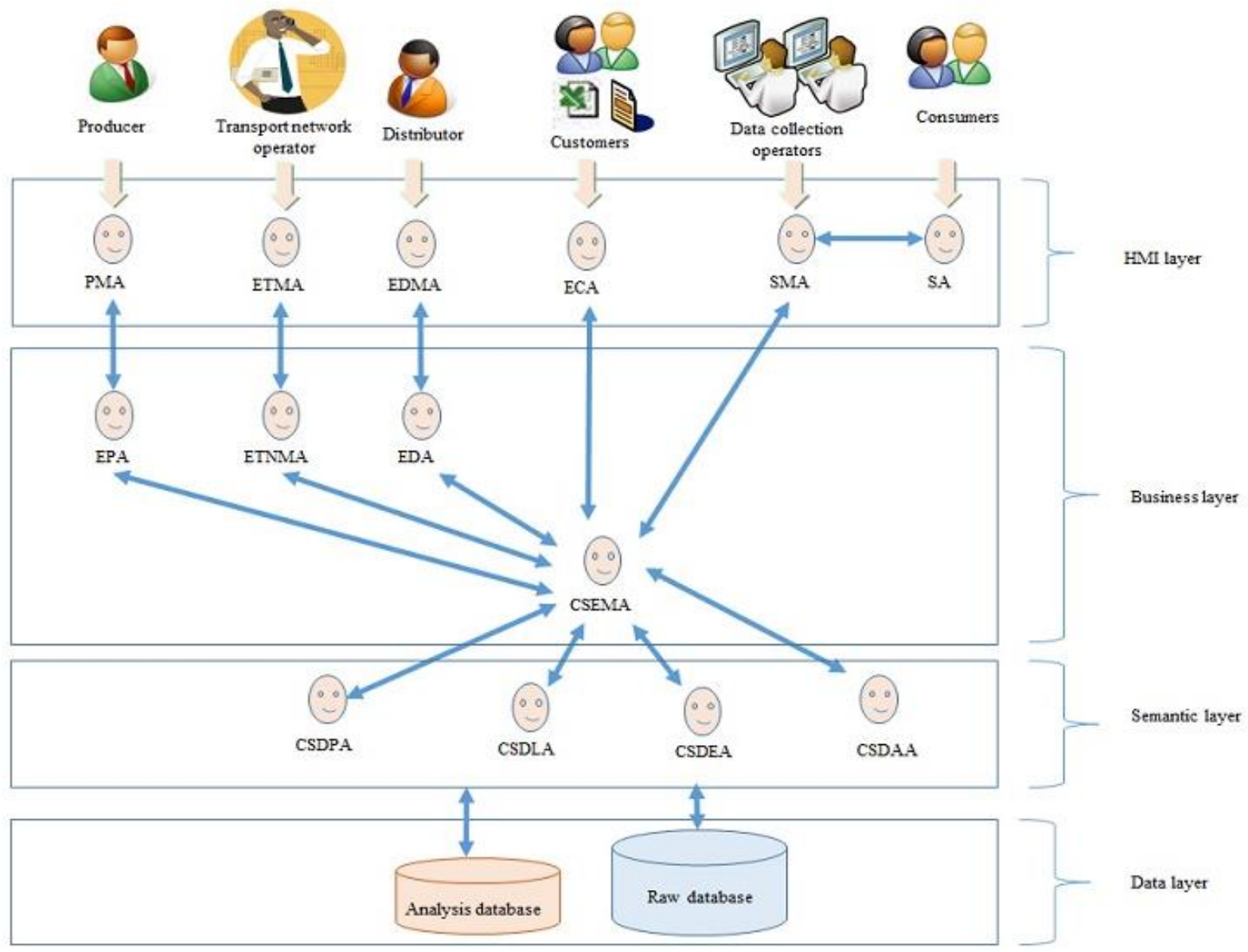

Fig.3. Multi-agent architecture per layer

\subsection{Multi-agent interaction cycle}

The multi-agent system comprises four main stages, which are data collection, receipt of requests, processing of requests and data storage:

- Collection is characterized by the transmission over the water of data from smart meters ;

- Receiving requests represents the handling of requests from different users of the system in order to obtain a result ;

- Processing of requests symbolizes the operations carried out by the system producing the result corresponding to a user request ;

- Data storage corresponds to the recording of raw, structured or analytical data making it possible to respond to all user requests.

The links and operations that take place between the different stages of the multi-agent system include:

- Data injection into the database ;

- Replacement of the erroneous data identified by their correction either by the retransmission of these data, or during their processing ;

- Orientation of requests;

- Reporting of the results ;

- Data warehouse communications and queries. 


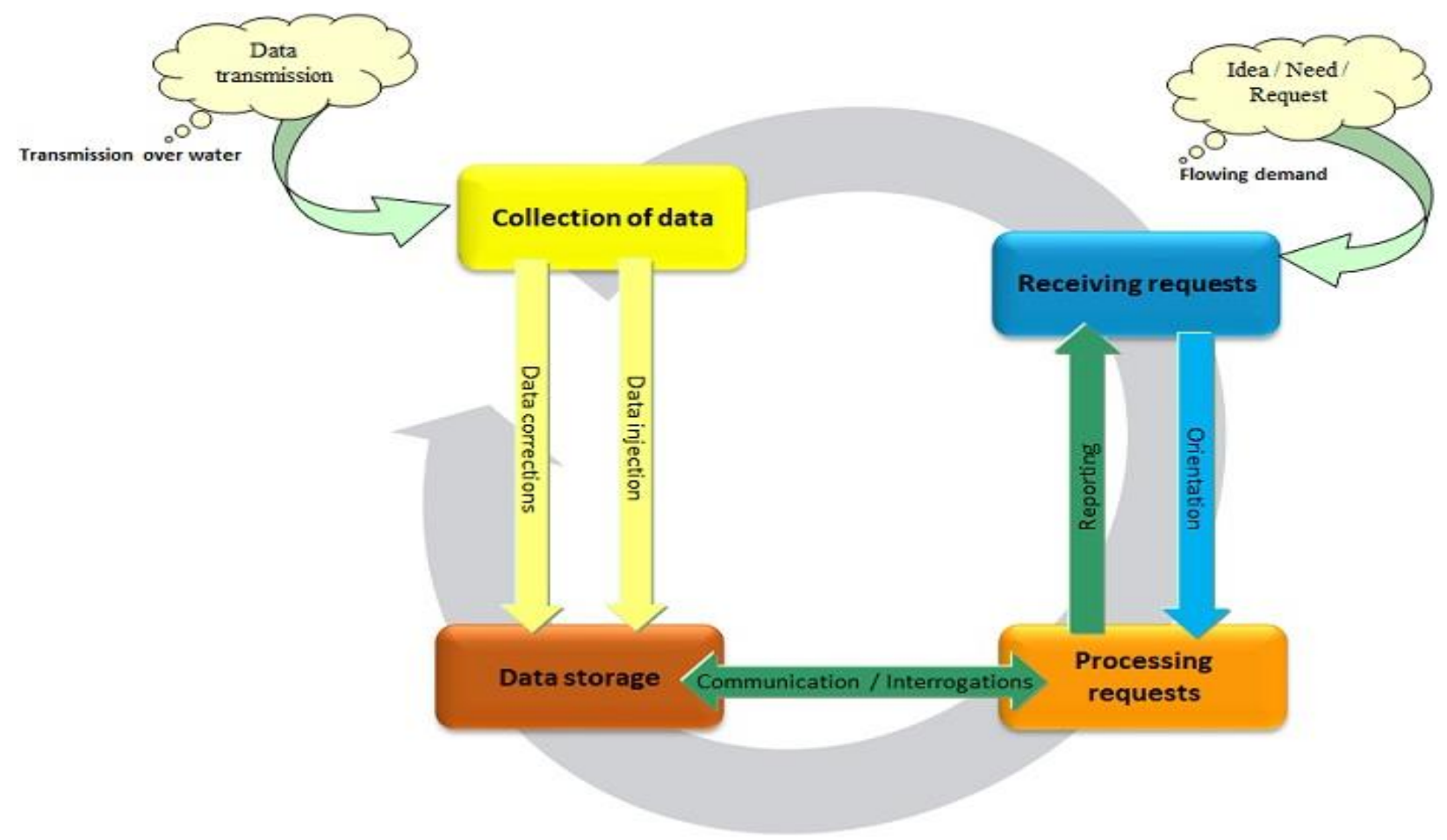

Fig.4. Functional process of agent interaction

\section{Detailed Presentation of Agents}

\subsection{Sensors Agent (SA)}

The sensors evaluate the electricity consumption for each point of electricity consumption and transmit the consumption value to the smart meter to which they are attached at specific times. The consumption value transmitted is then calculated between the last moment of transmission and the new instant.

Since measurement data is ordered at the source, it can be stored in the customer database in an orderly fashion. The advantage of scheduling data from the customer database as early as the insertion phase in the central database lies in the facilitation of the processing operations of this gigantic data warehouse [42].

This situation implies that the sensor associated with each measuring point sequentially go back up the measurement data $[43,44]$.

The data collection mechanism, therefore, operates efficiently to the insertion of the measurement data in the central database. The main point of attention, therefore, lies in the implementation of a mechanism for recording data in the order of their dates within the smart meters [45].

We have identified two scenarios regarding smart meter data scheduling that can be sequential or not. Each situation has two cases (ordered or not). Let us highlight the process of recording the data of two measuring points $\mathrm{P} 1$ and $\mathrm{P} 2$ in the customer database.

Measurement data arriving sequentially and one at a time

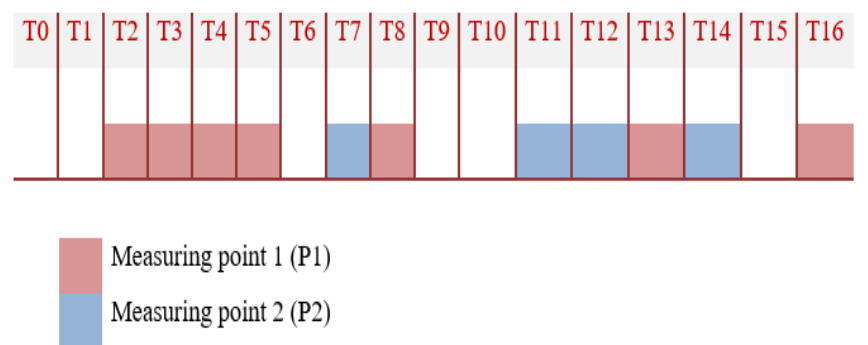

Fig.5. Representation of a sequential and non-simultaneous sequencing of data from two measuring points 


\section{Observations 1:}

- The data of the different measuring points arrive one after the other;

- A single measuring point transmits data at a given moment (at times T7 and T14, only the point P2 transmits data).

Measurement data arriving sequentially and several at a time

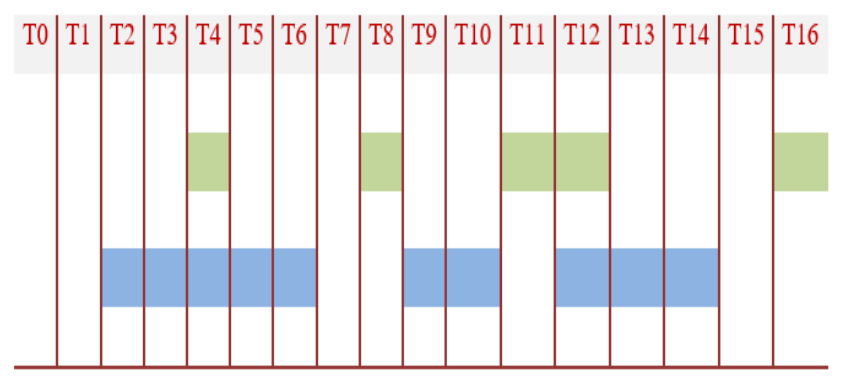

Measuring point $1(\mathrm{Pl})$

Measuring point 2 (P2)

Fig.6. Representation of a sequential and simultaneous sequencing of the data of two measuring points

Observations 2:

- The data of the different measuring points arrive one after the other;

- Several measuring points transmit data at the same time (at times T4 and T12, points P1 and P2 transmit data).

Measurement data arriving unordered and one at a time
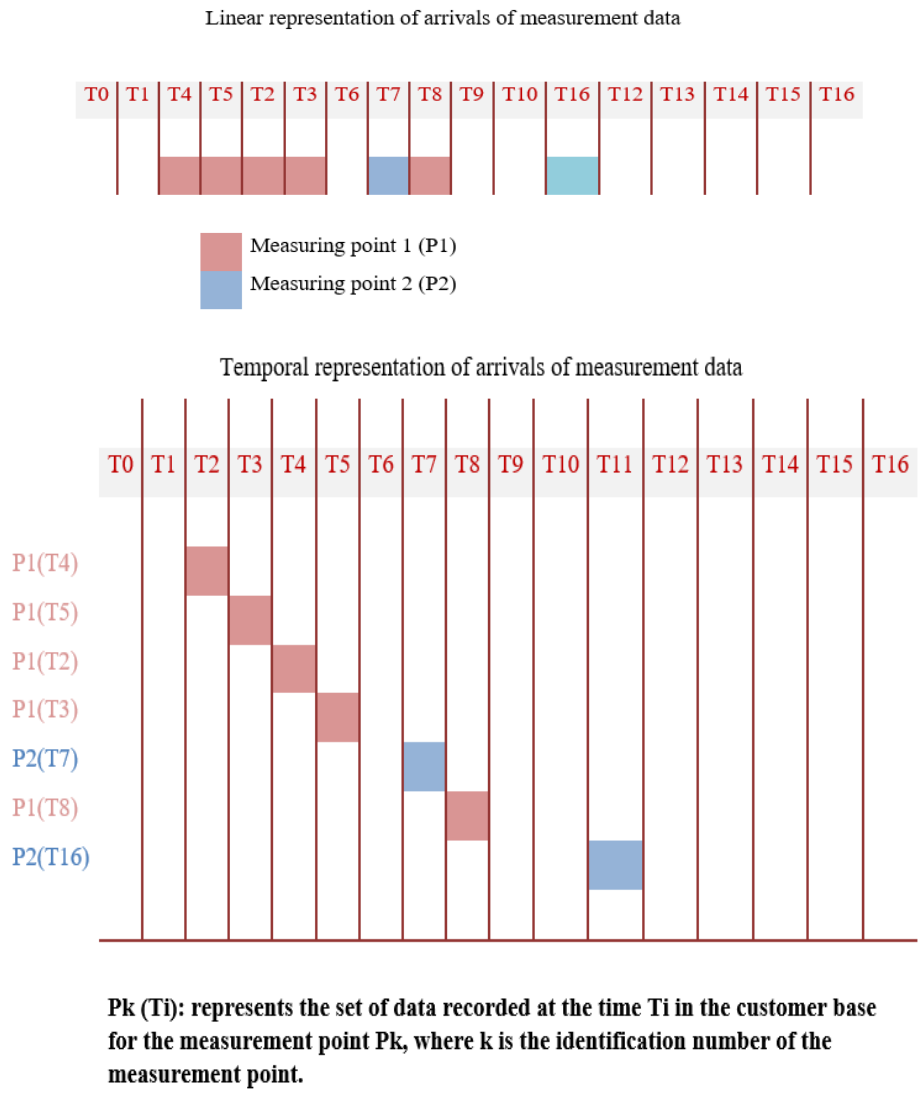

Fig.7. Representation of non-sequential and non-simultaneous scheduling of data from two measuring points 
Observations 3:

- The data collection mechanism recovers unordered data from smart meters [46];

- The measurement data of the point P1 do not arrive in the order at the instants (T2, T3, T4, T5), likewise for the point $\mathrm{P} 2$ at the instant $\mathrm{T} 11$;

- Only one measurement data is recorded at a given time.

Measurement data arriving unordered and several at a time

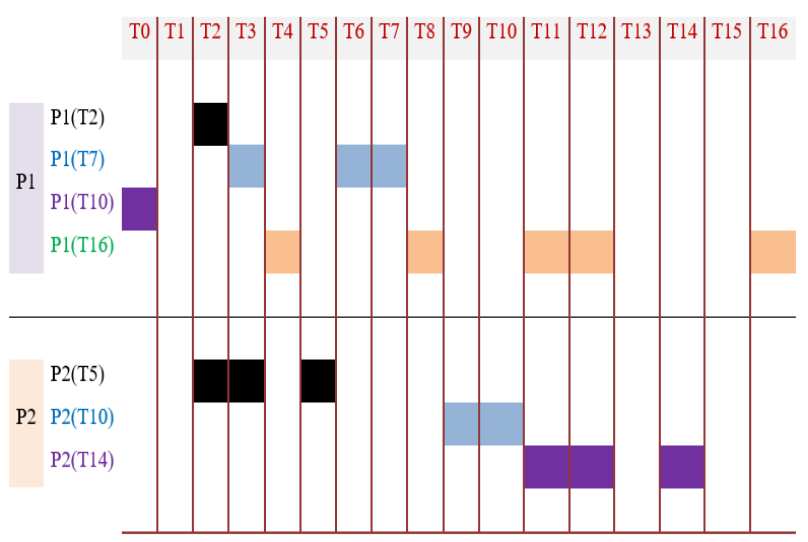

$\mathrm{Pk}$ (Ti): represents the set of data recorded at the time Ti in the customer base for the measurement point $\mathrm{Pk}$, where $\mathrm{k}$ is the identification number of the measurement point.

Fig.8. Representation of non-sequential and simultaneous scheduling of data from two measuring points

Observations 4:

- Measurement data is saved in the customer system late or in real time;

- The measurement data of P1 and P2 overlap (at times T2, T3, T11, T12) but without necessarily concerning the same moments;

\section{General observations of measurement data}

The analysis of the arrival of the measurement data within the smart meter makes it possible to observe the following facts:

- The data collection mechanism can recover unordered data from smart meters;

- The data of different measuring points can arrive at the same time in the customer database regardless of their actual dates;

- No loss of data is acceptable.

- The common point to all data recorded in the smart meter at any time (Ti) is the arrival date (Ta).

How then to order such a large number of measurement data while optimizing the performance of the data collection mechanism?

This operation implies that the sensors (measuring points) associated with each smart meter back the measurement data in real time or late without loss of measurement data being tolerated [47].

General observation: a careful analysis of the different presentations (scenarios and cases) shows that the common point to all measurement data arriving within the smart meter is the arrival date. This observation is all the more accurate than the measurement data from the sensors are ordered or not.

It is therefore sufficient to stamp all measurement data arriving at the smart meter by their arrival dates to be able to recover all of these data in an orderly manner and without loss of information.

\subsection{Smart meters Agent (SMA)}

They are the basis of the research work. Their contributions are a real asset to the computerization of the electric power sector. Smart meters can be placed at all levels of exchange between the main actors in the electricity value chain. They are the ones that facilitate the collection and processing of exchanged data. The exchange of measurement data involves putting then in transfer formats. As for the reception of the data of the smart meters, it concerns their collection from the sensors and their recording within the smart meter.

The measurement data may be collected without loss of information to reproduce an accurate bill of customer 
consumption and to provide each customer with a set of services based on collected electricity consumption data [48].

The sensors data collection mechanism transfers the available data to the meters at any time. This data recovery must be secure and can be done either:

- real-time (direct recording of data within the smart meter);

- offline (recording of data is done whenever possible within the smart meter).

\section{Collecting sensor data to the smart meter database}

For the collection of data within the smart meter, it is sufficient to add a parameter "ARRIVAL_DATE" to the "MEASURE" table of the customer database to facilitate the scheduling and collection of measurement data from the sensors.

The "MEASURE" table is the representation in the customer database of all types of measurement coming from the sensors. The new parameter "ARRIVAL_DATE" will allow the scheduling of all the measurement data regardless of whether the data from the sensors connected to the smart meters are transmitted sequentially or not to the smart meter. The data collection mechanism of the smart meter will, herefore, insert the measurement data in the customer database with the information "ARRIVAL_DATE". Thus, all the measurement data arriving at the same time at the smart meter level are inserted into the customer database with the same arrival date. We, therefore, define the measurement data table as follows:

Table 3. Representation of a measuring point

\begin{tabular}{|c|c|c|}
\hline \multicolumn{2}{|c|}{ MEASURE } \\
\hline Feature & Format & Description \\
\hline ID_POINT & Integer & $\begin{array}{c}\text { Unique identifier of the type of } \\
\text { measure }\end{array}$ \\
\hline MEASURE_TYPE & String & Type of measure \\
\hline TIMESTAMP & $\begin{array}{c}\text { AAAA-MM- } \\
\text { JJThh:mm:ss+hh:mm }\end{array}$ & $\begin{array}{c}\text { Specifies the date and time of } \\
\text { the measurement }\end{array}$ \\
\hline VALUE & Integer & Value of the measure \\
\hline ARRIVAL_DATE & $\begin{array}{c}\text { AAAA-MM- } \\
\text { JJThh:mm:ss+hh:mm }\end{array}$ & $\begin{array}{c}\text { Specifies the date and time of } \\
\text { receipt of the measurement at } \\
\text { the smart meter }\end{array}$ \\
\hline
\end{tabular}

There is no synchronization constraint between the smart meter system and the sensor systems [49]. This situation prevents the meter from malfunctioning in the event of a sensor failure and allows the smart meter to warn of a sensor's failure in the case of an unusually long period of non-receipt of this sensor's data.

\subsection{Central System Electricity Management Agent (CSEMA)}

The central system plays the role of regulation at the level of all the actors of electricity value chain for each country. The processing, analysis, and sending of data involves scaling them to annual, monthly, daily and hourly dimensions. It must be placed at the level of an independent authority in charge of the regulation of the energy sector. It is not the role of the regulator to calculate penalties arising from the application of contracts between the various actors in the electricity value chain. The regulator can be seized in the event of litigation for the control of data subject to litigation and for this reason; the data exchanges must include both the sending of raw data and aggregated data to the central system.

\section{Basic mechanism for collecting measurement data in the central system} either:

The central system must guarantee high performance. We advocate the creation of an archive database that can be

- A replication of the entire central database on another system for production of other additional data such as aggregation data and analysis data;

- A replication of the primary database and other generated data (aggregations, analyzes, etc.) on another system.

The customer database can be placed at the smart meter level in the data collection process, and the central database can be set at the Advanced Meter Management (AMM) level.

\section{Collecting data from smart meters databases to the central database}

The mechanism of data collection to the central database will remount all the measurement data stored at the smart meter according to the parameter "ARRIVAL_DATE".

The central database can be seen as one or more relocated databases with other actors in the electricity value chain (suppliers, customers, etc.). Each actor constitutes its central database according to its rights of access to data of the 
customer databases.

The mechanism for collecting data to the central database, therefore, consists of feeding a set of databases from data of customers' databases. In some cases, it will be necessary to transfer raw data from the central database to other databases for the production of analysis data according to the domains concerned, and in other cases, the transfer will be limited only to the aggregated or analyzed data generated from the central database.

Constraint: measurement data of customer databases can have identical identifiers. It is, therefore, necessary to differentiate these data through a unique identifier.

\begin{tabular}{|c|c|c|c|c|}
\hline $\begin{array}{c}\text { MESURING } \\
\text { POINT }\end{array}$ & ID_POINT & MEASURE_TYPE & TIMESTAMP & VALUE \\
\hline P1 & 1000111 & INDEX & $\begin{array}{c}2018-01-30 \\
01: 00: 00+02: 00\end{array}$ & 3 \\
\hline P2 & 1589111 & INDEX & $\begin{array}{c}2018-01-31 \\
01: 00: 00+07: 00\end{array}$ & 12 \\
\hline P3 & 1428111 & INDEX & $\begin{array}{c}2018-02-01 \\
01: 00: 00+03: 00\end{array}$ & 2 \\
\hline P4 & 1000111 & INDEX & $\begin{array}{c}2018-02-02 \\
01: 00: 00+09: 00\end{array}$ & 9 \\
\hline
\end{tabular}

Fig.9. Example of different measuring points with the same identifier

In the table above, all rows represent data from separate measuring points. We note, however, that the measuring points P1 and P4 have identical identifiers. These situations should be avoided by adding a parameter, we call "ID_SOURCE", to uniquely identify the measuring points of each source.

We assume in the design that the identification number of each smart meter "REF_SMART_METER" is unique. However, a customer can have several smart meters, the reference of the customer "REF_CUSTOMER" is not enough because it can be associated with several smart meters. Therefore, we will define the "ID_SOURCE" as a combination of information including the smart meter number and the reference for each customer. The "ID_SOURCE" will be the unique element for the identification of different measuring points of all data sources.

It is also possible to add a new table "OCCUPANT" in the database model to take into account the occupant information in each zone or group of zones. This information will help manage housing taxes, TV royalties, and other taxes. These are examples of possible applications with a data warehouse that can cover a large part of the population of all localities in a country.

In the customer database, we will add the parameters "REF_CUSTOMER" and "REF_SMART_METER" but the table "SOURCE" which data structure is defined as follows will be created only in the central database:

Table 4. First representation of a source

\begin{tabular}{|c|c|c|}
\hline \multicolumn{2}{|c|}{ SOURCE } \\
\hline Feature & Format & Description \\
\hline ID_SOURCE & Integer & $\begin{array}{c}\text { The unique identifier of the source representing the } \\
\text { combination of smart meter number and customer } \\
\text { reference. }\end{array}$ \\
\hline REF_CUSTOMER & String & $\begin{array}{c}\text { Unique reference allowing the identification of the } \\
\text { customer regardless of the number of his smart meter }\end{array}$ \\
\hline REF_SMART_METER & String & Unique reference to identify the meter. \\
\hline
\end{tabular}

We also modify the "MEASURE" table of the central database by adding the parameter "ID_SOURCE" and other parameters like the unit "UNIT" and the step of time "TIME_STEP":

Table 5. Improved representation of a measuring point

\begin{tabular}{|c|c|c|}
\hline \multicolumn{2}{|c|}{ MESURE } \\
\hline Feature & Format & Description \\
\hline ID_SOURCE & Integer & Unique identifier of the source. \\
\hline ID_POINT & Integer & Unique identifier of the measure. \\
\hline MEASURE_TYPE & String & Type of measure \\
\hline TIMESTAMP & AAAA-MM-JJThh:mm:ss+hh:mm & Specifies the date and time of the measurement. \\
\hline VALUE & Integer & $\begin{array}{c}\text { Specifies the date and time of receipt of the } \\
\text { measurement at the smart meter. }\end{array}$ \\
\hline ARRIVAL_DATE & AAAA-MM-JJThh:mm:ss+hh:mm & $\begin{array}{c}\text { Indicates the unit of measurement for load curves } \\
\text { and daily indexes: 'Wh' value (Watt / hour) and for } \\
\text { maximum powers: 'W' (Watt). }\end{array}$ \\
\hline UNIT & String & $\begin{array}{c}\text { Specifies the length of time between two successive } \\
\text { arrivals of measurement data. }\end{array}$ \\
\hline
\end{tabular}


The data collection mechanism must be set up so that only data of the sources previously set in the central database can be collected. This condition makes it possible to exclude the collection of data from customers not yet configured in the central system.

The key "ID_SOURCE" constituted by the pair (REF_CUSTOMER, REF_SMART_METER) makes it possible to distinguish all the measurement data coming from the different smart meters.

The transfer of data from one information system to another is conditioned by the general regulations on the protection of personal data. Indeed, any transfer of data from a customer database to the central database must be done in compliance with the general regulation on the protection of personal data applicable to each country. This regulation is in several states continually evolving to take into account the many technological changes especially those relating to Big Data handling personal data.

The central database is similar to the customer database in the limit of the information shared by these two databases. The mechanism of data collection to the central database needs to know at every moment the date of last data collected from the smart meter "LAST_COLLECTION_DATE" which corresponds to the last time for which data were transferred in the central database.

The table "SOURCE" evolves in the central database to take into account the parameter "LAST_COLLECTION_DATE". In the case, where we have multiple sources of data collection (buildings and neighborhoods), the last date of data collection for each source should be defined. The collection of data from a source supposes the sorting of its measurement data in order of arrival dates "ARRIVAL_DATE" at level of the smart meter. The last collection date "LAST_COLLECTION_DATE" corresponds to the arrival date of last collected data. The data collection is therefore based on the order of arrival dates of the measurement data for each source.

So, we add to each source, the last data collection dates "LAST_COLLECTION_DATE":

Table 6. Improved representation of a source

\begin{tabular}{|c|c|c|}
\hline \multicolumn{2}{|c|}{ SOURCE } \\
\hline Feature & Format & $\begin{array}{c}\text { The unique identifier of the source representing the } \\
\text { combination of smart meter number and customer } \\
\text { reference }\end{array}$ \\
\hline ID_SOURCE & Integer & $\begin{array}{c}\text { Unique reference allowing the identification of the } \\
\text { customer regardless of the number of his smart meter }\end{array}$ \\
\hline REF_CUSTOMER & String & Unique reference to identify the meter \\
\hline $\begin{array}{c}\text { REF_SMART_ } \\
\text { METER }\end{array}$ & String \\
DAST__ & AATION_ & Last date of data collection \\
\hline
\end{tabular}

Scheduling of data collection from smart meters to the central system

The data collection must be able to retrieve all customers' information including detecting changes (data transfer system failure, smart meter failure) that have occurred since the last data transfer [50].

Securing the transfer of these data using data encryption is necessary.

There is also the need to transfer data between the customer and central systems at any time without loss of information and even in case of failure recovery [51]. For better efficiency of data transfer, the central system must know the last moment of data collection to continue the retrieval of information not yet recorded in the central database. Since the meter is gradually recording the measurement data, there is no problem in scheduling the measurement data.

The recovered data must sort the information available in the customers' database in ascending order of arrival dates of measurement data. In addition, only the central system knows when the last measurement from each smart meter was recorded. For this, the central system must have a date-type parameter that we call "LAST_COLLECTION_DATE", which in each case corresponds to the date of last measurement data stored in the central system for a given customer.

The insertion of each measurement data and the update of the last transfer date must be done in a transaction. The customer system must also expose a Web Service, which may be accessible by the central system for the retrieval of measurement data.

The central system must have a list of measuring points "LIST_MESURING_POINTS". This list must correspond to the list of points available in the customer system. 
Table 7. Last representation of a source

\begin{tabular}{|c|c|c|}
\hline \multicolumn{2}{|c|}{ SOURCE } \\
\hline Feature & Format & Description \\
\hline ID_SOURCE & Integer & $\begin{array}{c}\text { The unique identifier of the source representing the } \\
\text { combination of smart meter number and customer } \\
\text { reference. }\end{array}$ \\
\hline REF_CUSTOMER & String & $\begin{array}{c}\text { Unique reference allowing the identification of the } \\
\text { customer regardless of the number of his smart meter }\end{array}$ \\
\hline $\begin{array}{c}\text { REF_SMART_ } \\
\text { METER }\end{array}$ & String & Unique reference to identify the meter. \\
\hline $\begin{array}{c}\text { LAST_ } \\
\text { COLECTION_ } \\
\text { DATE }\end{array}$ & $\begin{array}{c}\text { AAA-MM-JJThh:mm: } \\
\text { ss+hh:mm }\end{array}$ & List of measuring points \\
\hline $\begin{array}{c}\text { LIST_ } \\
\text { MESURING_ } \\
\text { POINTS }\end{array}$ & String [1... N] & \\
\hline
\end{tabular}

The smart meter and the data collection system must ensure data security and fraud avoidance. For example, an order number indicating the change of the list of points is a safety measure. In the case of fraud, the fraudster is no longer able to find the value to establish trust and ensure the integrity of the communication between the customer system and the central system.

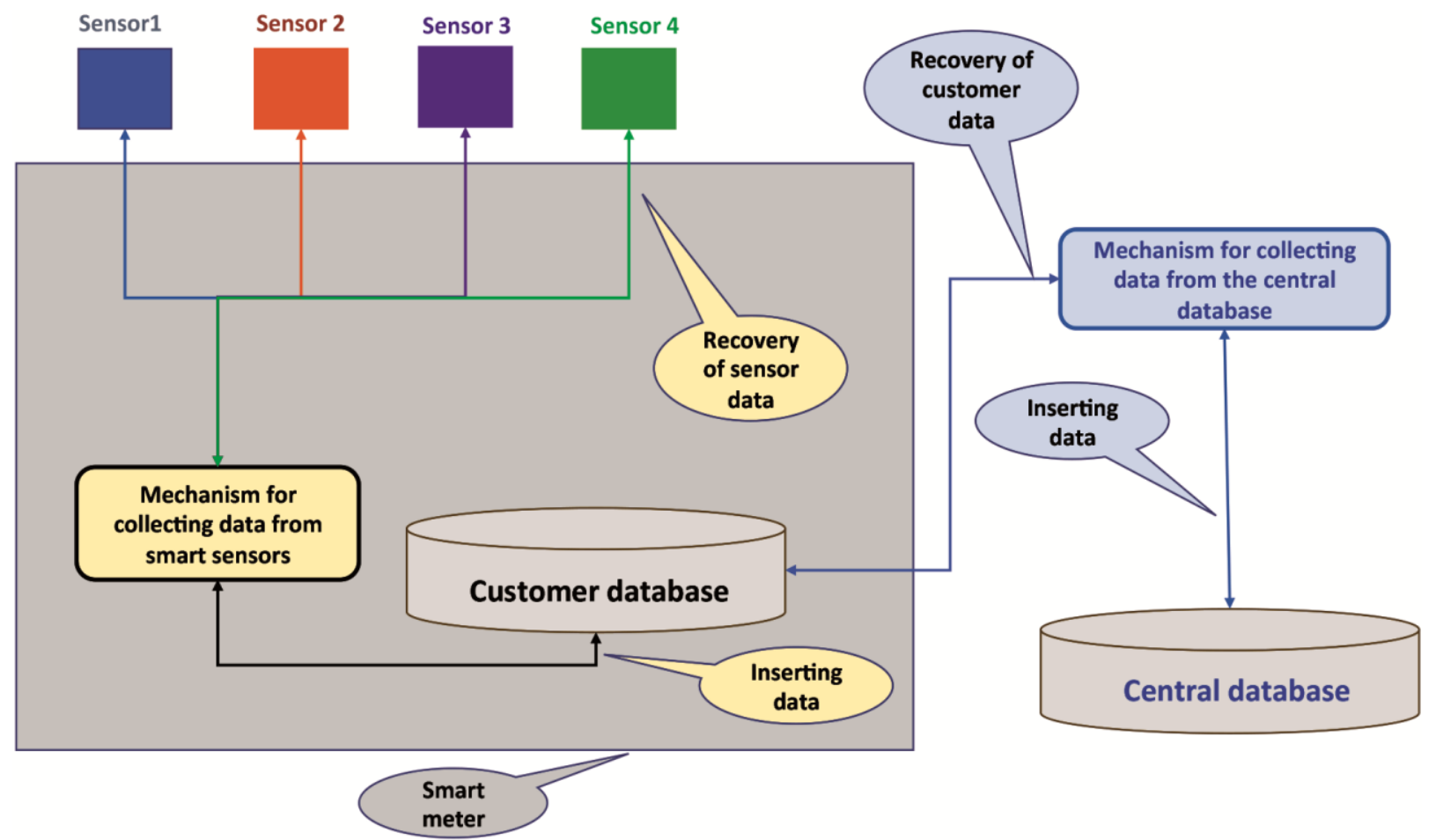

Fig.10. Schema for transferring measurement data from a customer system to the central system

Prerequisite: We consider that it is the central system only that initiates the connection to the customer system for the retrieval of measurement data.

Step 1: The central system calls a Web Service exposed by the customer system by sending it the order number and the last data collection date. It then appears that this smart meter must implement a process, which allows the central system to retrieve the measurement data for powering the primary database [48].

Step 2: It corresponds to the processing performed by the smart meter to transmit all measurement data to the central system. The smart meter must always keep in memory the last order number exchanged with the central system as well as the new order number in case of modification of the list of measuring points of the customer database. The first order number must be manually set at the smart meter to enable communication with the central system.

Step 3: Any change in the list of measuring points must be indicated to the central system. The customer system must, at each delivery of measurement data, compare its list of measuring points to that of the primary system. The comparison of the two records can be tedious especially when the measuring points are numerous. We then choose to define an order number which indicates any modification of the list of measuring points. When this variable is different in both systems, this means that the customer system must transmit to the central system the new order number and the 
list of measuring points in addition to the measurement data. In this case, the central system proceeds in a transaction to the updates of the order number and the old list of measuring points by the new one. However, when the order number has not changed, only the measurement data is transmitted to the central system.

Step 4: It corresponds to the processing performed by the central system for the integration of measurement data from all smart meters in the central database.

\subsection{Electricity Customer Agent (ECA)}

It plays the interface between the customer and the electricity distributor. It allows the end consumer to buy or sell electricity from a distributor. Electricity distributors can buy electricity from customers who produce it through their electricity generation facilities.

A customer cannot sell electricity directly to another customer. Only electricity distributors are qualified to carry out purchase and sale of electricity. A producer customer differs from a traditional customer in that he produces and sells electricity. The electricity data product by producing customers are transmitted to the electricity distributors, who then take care of the necessary compensations when drawing up the electricity bills of the customers. A customer can regulate his electricity production by stopping or starting his production of electricity as needed.

\subsection{Electricity Distributor Agent (EDA)}

This agent ensures the delivery of electricity to the customer or the withdrawal of the electricity produced by a customer for its provision on the distribution network.

Electricity distributors purchase electricity from power transmission operators and sale it to conventional customers. However, they can buy electricity directly from customers that produce electricity without going through electricity transmission operators. The purchase of electricity from customers is compensated between electricity consumed by the customer and that sold to the distributor. A distributor cannot buy electricity from another distributor. All of the distributor's business activities, including delivery, analysis of the distribution market and monitoring of distribution network installations are part of the management of electricity distribution.

\subsection{Electricity Transmission Networks Manager Agent (ETNMA)}

It enables communication between electricity distributors and transmission system operators in order to facilitate the transport of electricity to distribution points marking the separation between the transmission networks and the distribution networks.

Transmission System Operators (TSOs) are responsible for the purchase of electricity from producers and the sale of electricity to distributors. They are in charge of monitoring electricity transmission networks, detecting faults, detecting theft of electricity and balancing electricity transmission networks. The TSO also has the mission to analyze at any time the needs of distributors and producers to ensure the balancing of the electricity transmission network by ordering shutdowns and start-ups of electricity production at level of producers of electricity. All functional activities of the Transmission System Operator, including electricity delivery, transmission market analysis, and monitoring of transmission system facilities, are part of the management of a transmission.

\subsection{Electricity Producer Agent (EPA)}

It is in charge of exchanges between electricity producers and transporters, in particular the purchase of the electricity produced and its transport.

Large electricity producers sell electricity produced to transmission system operators. Small producers (customers that produce electricity) sell their electricity directly to electricity distributors. Transmission system operators are, however, responsible for monitoring the electricity production facilities of electricity producers. Electricity distributors as well as network operators may be responsible for monitoring the installations of producer customers.

\section{Interactions between the Systems of the Smart Grid}

\subsection{Multi-agent smart grid based on exchanges within information systems}

In this model, exchanges with the central system are done through the information systems of the actors in the electricity value chain. This smart grid has the advantage of clarifying the exchanges at all levels of communication between the actors [52]. It also allows specific exchanges to the needs of each actor [36]. Its main disadvantage lies in the multiplicity of exchanges, which allow, however, to multiply the levels of verification and analysis of data. 



Fig.11. Exchange circuit based on exchanges with information systems

\subsection{Multi-agent smart grid based on exchanges with smart meters}

This model is based on the exchange features offered by smart meters [53]. In this model, all the exchanges between the central system and actors of the electricity value chain are done through smart meters. The intelligence of the metering system rests on that of smart meters. This system has the advantage of facilitating the consensus on access to data, the standardization of data exchanged between all actors and the implementation of functionalities relating to the needs of each actor. Its disadvantage lies in the provision of a large amount of processing power and data storage at the level of smart meters.

\subsection{Multi-agent smart grid based on mixed exchanges with the central system}

In this model, exchanges of information are possible between the actors and the central system on one hand and between the actors and the smart meters on the other hand. It has the advantage of allowing the implementation of other exchanges of data or specific functionalities [54]. This system can also be based on conventional data exchange standards or continue to use existing exchanges. It is a hybrid model to exploit the advantages of the two previous models but also to inherit their disadvantages. 


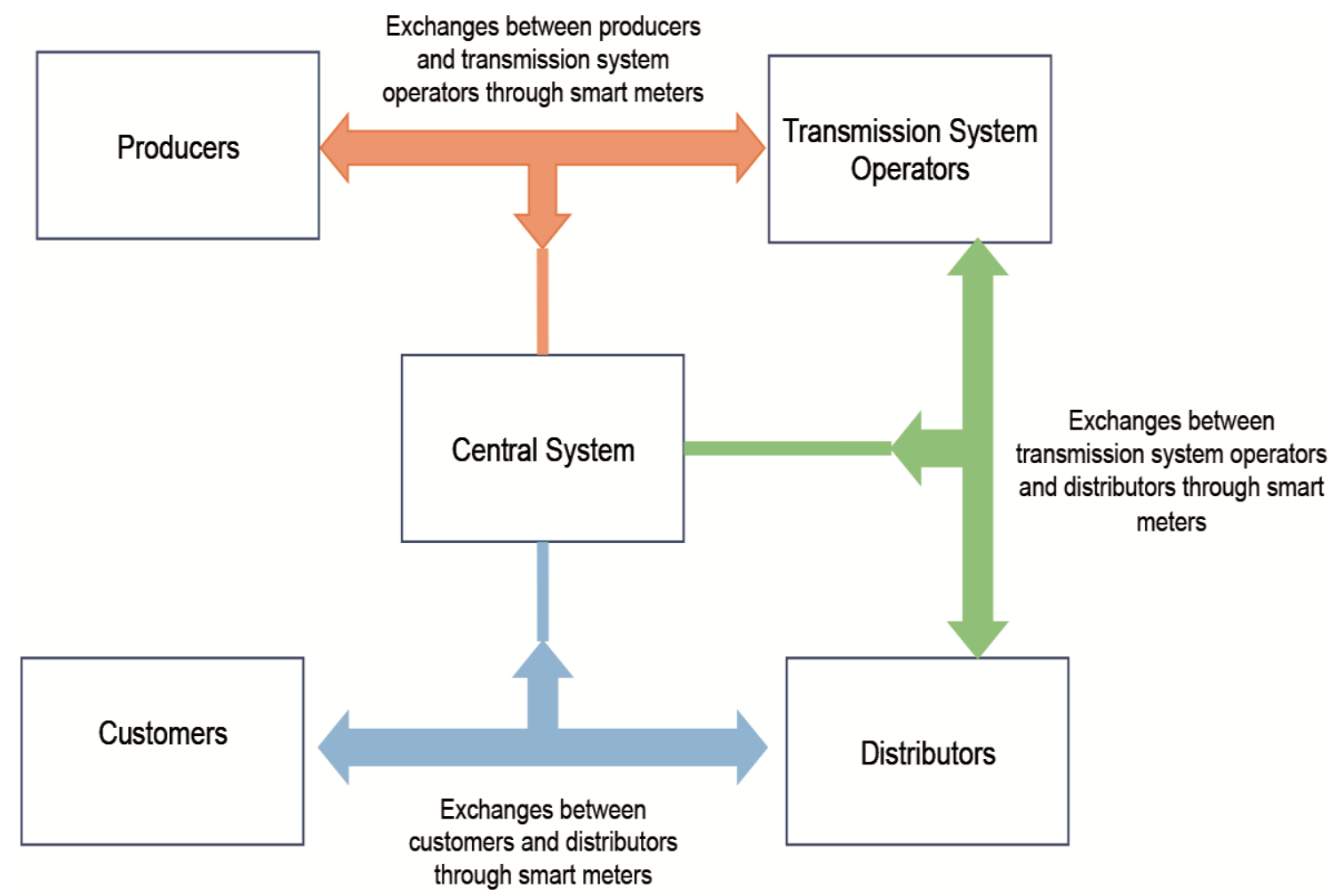

Fig.12. Exchange circuit based on exchanges with smart meters

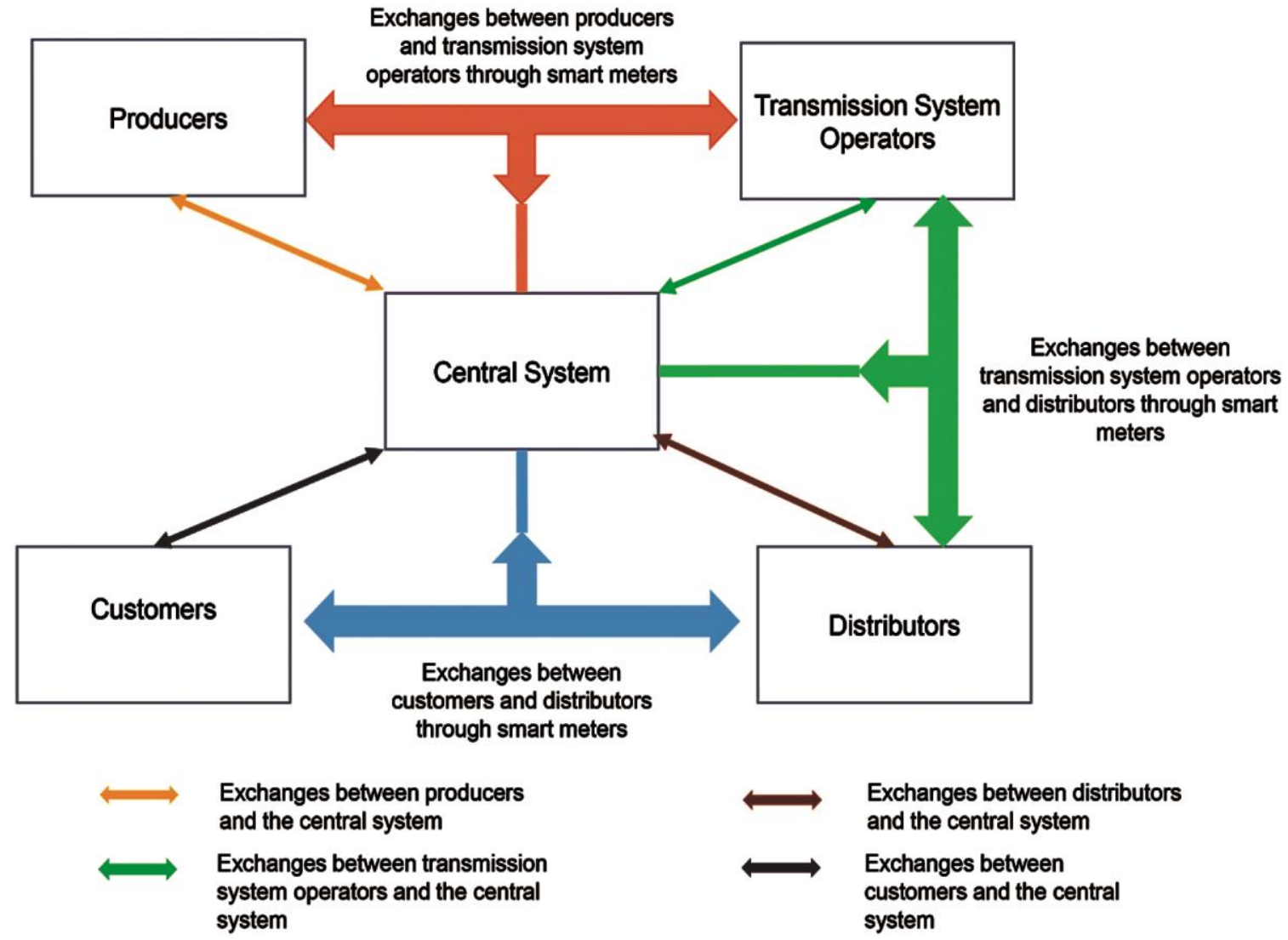

Fig.13. Mixed circuit of exchanges between the central system and the actors of the value chain of electricity 


\section{Central System Architecture}

\subsection{Central system Functional architecture}

All actors in the electricity value chain can have a technical architecture seems to that of the central system. Besides, the technologies of different interlocutors must be interoperable. The implementation of data exchange formats would facilitate the sharing of information and the implementation of computer processing for each stakeholder.

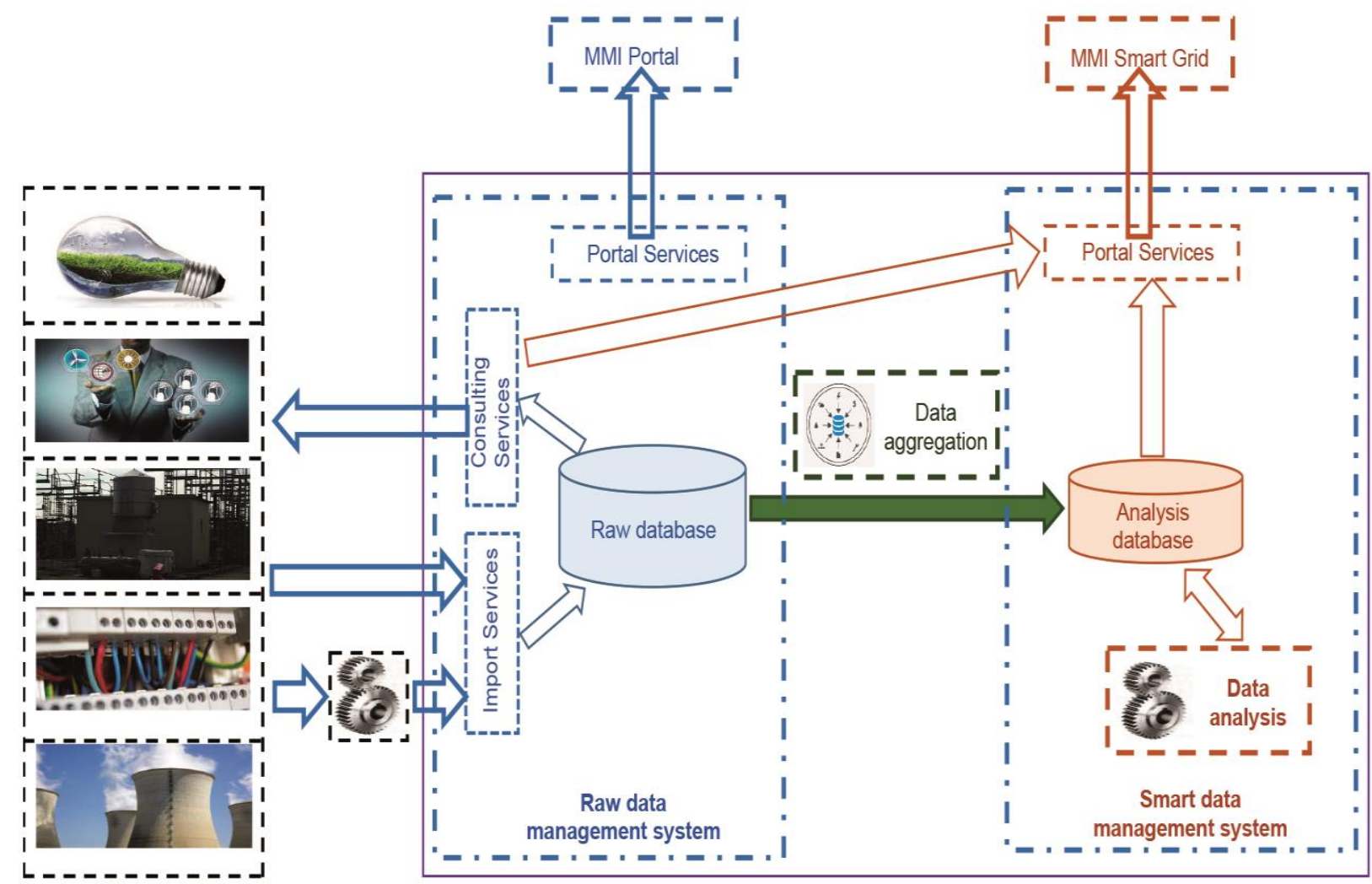

Fig.14. Functional architecture of the central multi-agent system and interactions with other actors in the electricity value chain

\subsection{Central system application architecture}

This architecture highlights the separation of the data access layer and the data exposure layer. This choice aims to standardize the presentation of data to all customers but also to allow each customer to implement agent specific to its business operations. The choice of application technologies is part of a concern to facilitate the interoperability of the exchanges independently of the characteristics of the IT infrastructures of the customers. 


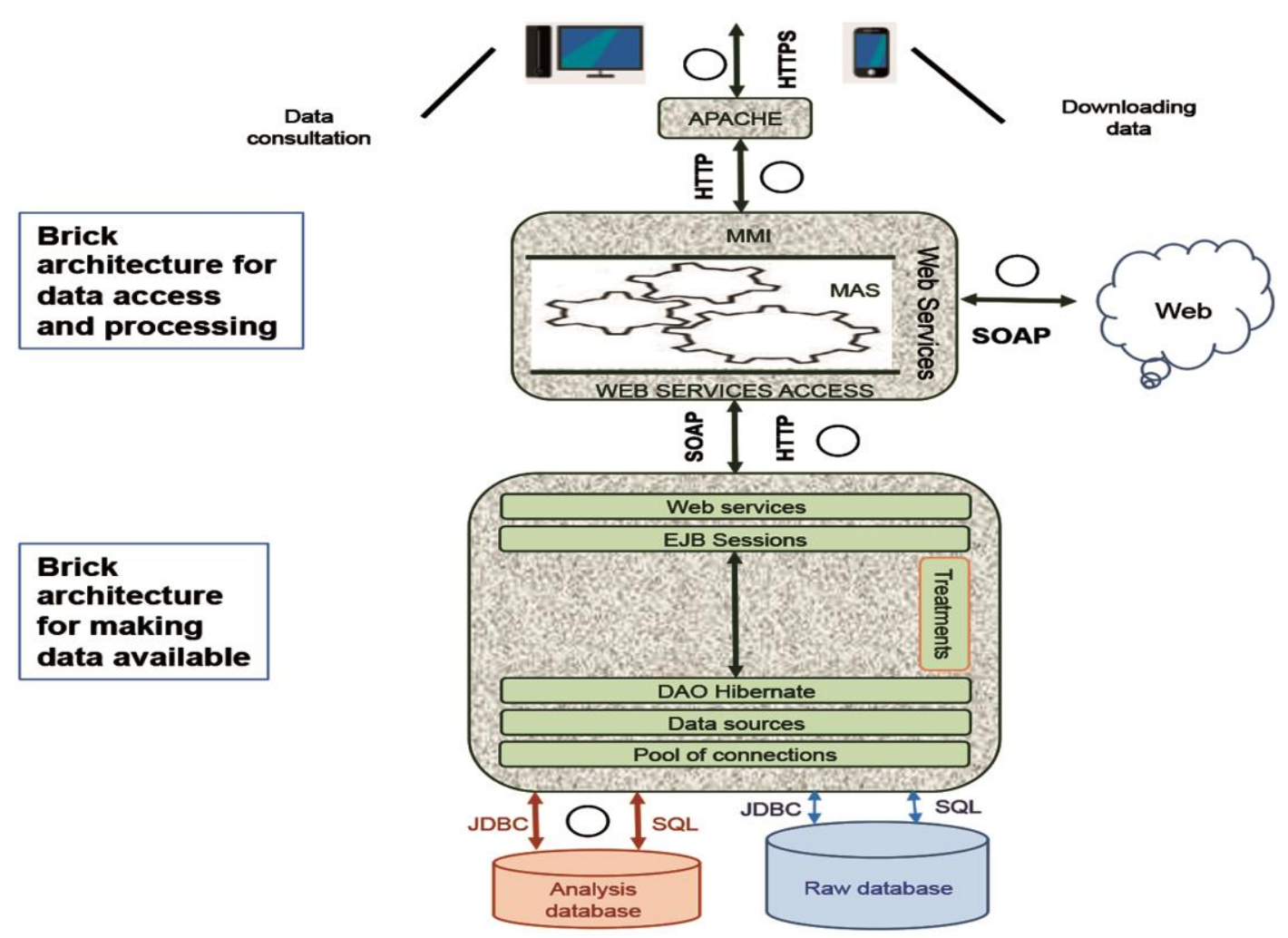

Fig.15. Presentation of the application architecture for the central system

\section{Tests and Performance Measurement of the Proposed Multi-Agent System}

The proposed system has not yet been tested. Indeed, the implementation of these tests depends at a minimum on the choice of a smart meter model, a smart sensor model and the data collection platform. The choice of the smart meter model and the lack of consumption data were the major obstacle to the implementation of tests. The most remarkable finding is that most countries have designed their own smart meter models based on their specific needs. Therefore, technical and functional needs must prevail in the design and in the choice of a smart meter. There are African institutions in charge of electricity management issues capable of leading this work and defining the orientations to be taken at regional and sub-regional levels. We unfortunately meet in Africa the lack of information on future strategies related to the choice of smart meters intended for automatic measurement of electricity consumption.

Several important characteristics should be taken into consideration:

- A reasonable price in relation to the context of its deployment;

- Ease of configuration and maintenance of the smart meter;

- $\quad$ Ease of wiring and management of the technical installation;

- Remote control of inputs and outputs;

- Battery-free operation with nevertheless an internal clock for synchronizing the transmission of consumption data to the data collection platform;

- An alert mechanism in the event of unauthorized opening or change of meter parameters;

- A cut-off switch integrated into the meter to prevent any modification to the electrical panel;

- A device based only on standardized components easily available on the market.

The absence of tests does not, however, prevent us from providing some elements that may guide on the performance of the proposed multi-agent system. It is indeed possible to identify a few points that play in favor of the performance of the proposed system. There are methods of data collection, transfer and sequencing that help to make data available and ready for use in the central data storage system. In addition, the calculations likely to degrade the performance of the system were limited thanks to the conceptual approaches used. Below is a list of elements that promote the good performance of our multi-agent system:

- Data collection requires the central system to know the different measurement points associated with each smart meter. The update of the list of measuring points occurs only when changes have been made to this list;

- Data scheduling at both smart meter level and central system level avoids any application of data scheduling 
algorithms by saving a significant cost of processing time that would have resulted in degradation of system performance. Indeed, the application of scheduling algorithms to such large data will certainly have the impact of reducing the performance of the system.

- The transfer of data from the smart meters to the central system is done without any need for scheduling the data retrieved within the smart meters. In fact, the ordering of data within the central system is carried out at the very moment of the integration of this data into the central system. The transfer only involves saving the last collection date throughout the data collection process of each smart meter;

- The multi-agent system paradigm used for the design of the proposed system also has the advantages of modularity, reliability, speed of simultaneous processing of tasks and ease of maintenance.

\section{Conclusion}

This work highlights an efficient management of private data from smart meters by scheduling them in the order of their arrival dates. In addition, the collection of these data to a central processing system must be reliable. The reliability of data collection within the primary system relies in part on pre-processing measurement data at the smart meter level.

We found some articles on scheduling and data collection in smart metering systems. We present through this work another approach to scheduling and collecting data from intelligent metering systems. This work also highlights the link between scheduling and smart metering data collection from sensors to the central system. This work shows the importance of facilitating the collection of data from metering systems through the scheduling of data.

The significant contribution of this work is the facilitation of the scheduling of different measurement data irrespective of the order of their arrivals both at the smart meter level and at the central system level.

Data collection mechanism will help to:

- Quickly identify breakdowns on the electricity network by setting up automated systems ;

- Detect fraud or attempted fraud ;

- Create a data analysis center for energy savings and predictive analysis ;

- Transfer data to the concerned actors;

- Set up analysis and visualization tools on data from smart meters ;

- Facilitate the balancing of consumption and production according to demands, constraints of production and supply of electricity.

It is certain that real-time access to electricity data will encourage the development of new opportunities for the smart meters (data crossover and new energy services). The development of services downstream of smart meters will stimulate competition in the electricity markets. The consumer will be able to choose the price offer that corresponds to his lifestyle and will be able to analyze the elements that may contribute to the reduction of the cost of his electricity bill These advances will be greater with the liberalization of the electricity supply markets. Smart grids will thus allow the implementation of pricing models including new offers that will promote the price elasticity expected by consumers.

Throughout this work, we have sought to simplify the management of data from intelligent electrical systems by justifying the use of the arrival date of measurement data in the central storage system. This choice constitutes an optimization of data processing both at the level of smart meters and at the level of the data centralization system, in particular because of the large volume of this data. We also design a multi-agent system for electricity data management. The objectives are achieved by collecting, scheduling and centralizing data from intelligent electrical systems upstream of data analysis.

This work is intended as a clear desire to clarify the various issues in the design and implementation of an electricity management system. This approach also aims to create a favorable framework for the provision of a data warehouse ready for the application of numerous models of forecasting and analysis. We also plan to continue this work with other studies such as the proposal of a database model, aggregation methods and data analysis. The objectives of all this work are to pursue progressively the design of the proposed multi-agent system.

\section{References}

[1] Fadi Shrouf, Giovanni Miragliotta. Energy management based on Internet of Things: practices and framework for adoption in production management. Journal of Cleaner Production, Volume 100, 1 August 2015, Pages 235-246

[2] Alexander Martin Tureczek and Per Sieverts Nielsen. Structured Literature Review of Electricity, Consumption Classification Using Smart Meter Data. Energies 2017, 10(5), 584; https://doi.org/10.3390/en10050584.

[3] Athila Quaresma Santos, Renato Machado Monaro, Denis Vinicius Coury, Mario Oleskovicz. A new real-time multi-agent system for under frequency load shedding in a smart grid context. Electric Power Systems Research 174 (2019) 105851.

[4] Madeline Martinez-Pabon, Timothy Eveleigh, Bereket Tanju. Optimizing residential energy management using an autonomous scheduler system. Expert Systems With Applications 96 (2018) 373-387.

[5] Markus Mäsker, Lars Nagel, AndréBrinkmann, Foad Lotfifar, Matthew Johnson. Smart Grid-aware scheduling in data centres. 
Computer Communications 96 (2016) 73-85.

[6] Ilze Laicane, Dagnija Blumberga, Andra Blumberga, Marika Rosa. Reducing household electricity consumption through demand side management: the role of home appliance scheduling and peak load reduction. Energy Procedia 72 ( 2015 ) 222 229.

[7] Joshua D. Rhodes, Charles R. Upshaw, Chioke B. Harris, Colin M. Meehan, David A. Walling, Paul A. Navrátil, Ariane L. Beck, Kazunori Nagasawa, Robert L. Fares, Wesley J. Cole, Harsha Kumar, Roger D. Duncan, Chris L. Holcomb, Thomas F. Edgar, Alexis Kwasinski, Michael E. Webber. Experimental and data collection methods for a large-scale smart grid deployment: Methods and first results. Energy 65 (2014) 462-471.

[8] Xi Fang, Student Member, IEEE, Satyajayant Misra, Member, IEEE, Guoliang Xue, Fellow, IEEE, and Dejun Yang, Student Member, IEEE. Smart grid - the new and improved power grid: A survey. IEEE Communications Surveys \& Tutorials, Vol. 14, No. 4, Fourth quarter 2012.

[9] Nicola Bui ; Angelo P. Castellani ; Paolo Casari ; Michele Zorzi. The internet of energy: a web-enabled smart grid system. IEEE Network ( Volume: 26 , Issue: 4, July-August 2012 ).

[10] Hongxun Hui, Yi Ding, Qingxin Shi, Fangxing Li, Yonghua Song, Jinyue Yan. 5G network-based Internet of Things for demand response in smart grid: A survey on application potential. Applied Energy, Volume 257, 1 January $2020,113972$.

[11] Alireza Zakariazadeh, Shahram Jadid, Pierluigi Siano. Multi-objective scheduling of electric vehicles in smart distribution System. Energy Conversion and Management 79 (2014) 43-53.

[12] M.M. Eissa, A.A. Ali, K.M. Abdel-Latif, A.F. Al-Kady. Emergency frequency control by using heavy thermal conditioning loads in commercial buildings at smart grids. Electric Power Systems Research 173 (2019) 202-213.

[13] Raghu K. Ganti, Fan Ye, and Hui Lei, IBM T. J. Watson Research Center. Mobile Crowdsensing: Current State and Future Challenges. IEEE Communications Magazine • November 2011.

[14] Tanveer Ahmad, Hongcai Zhang, Biao Yan. A review on renewable energy and electricity requirement forecasting models for smart grid and buildings. Sustainable Cities and Society, Volume 55, April 2020, 102052.

[15] Rabiya Khalid, Nadeem Javaid, Fahad A. Al-zahrani, Khursheed Aurangzeb, Emad-ul-Haq Qazi and Tehreem Ashfaq. Electricity Load and Price Forecasting Using Jaya-Long Short Term Memory (JLSTM) in Smart Grids. Entropy 2020, 22(1), 10; https://doi.org/10.3390/e22010010.

[16] Géremi Gilson Dranka, Paula Ferreira. Towards a smart grid power system in Brazil: Challenges and opportunities. Energy Policy, Volume 136, January 2020, 111033.

[17] Gerwin Evers, Maryse M.H.Chappin. Knowledge sharing in smart grid pilot projects. Energy Policy, Volume 143, August $2020,111577$.

[18] M. Ourahou, W. Ayrir, B. EL Hassouni, A. Haddi. Review on mart grid control and reliability in presence of renewable energies: challenges and prospects. Mathematics and Computers in Simulation, Volume 167, January 2020, Pages 19-31.

[19] Dileep G. A survey on smart grid technologies and applications. Renewable Energy, Volume 146, February 2020, Pages 25892625.

[20] Mostafa Farhadi Moghadam, Morteza Nikooghadam, Amir Hossein Mohajerzadeh, Behzad Movali. A lightweight key management protocol for secure communication in smart grids. Electric Power Systems Research Volume 178, January 2020, 106024.

[21] Monica Alonso, Hortensia Amaris, Daniel Alcala and Diana M. Florez R. Smart Sensors for Smart Grid Reliability. Sensors (ISSN 1424-8220; CODEN: SENSC9).

[22] Muhammed Zekeriya Gunduz, Resul Das. Cyber-security on smart grid: Threats and potential solutions. Computer Networks, Volume 169, 14 March 2020, 107094.

[23] Ameema Zainab, Shady S. Refaat, Haitham Abu-Rub and Othmane Bouhali. Distributed Computing for Smart Meter Data Management for Electrical Utility Applications. 2020 Cybernetics \& Informatics (K\&I), DOI: 10.1109/KI48306.2020.9039899, IEEE

[24] Bassirou Diène, Joel J.P.C.Rodrigues, Ousmane Diallo, EL Hadji Malick Ndoye, Valery V. Korotaev. Data management techniques for Internet of Things. Mechanical Systems and Signal Processing, Volume 138, April 2020, 106564.

[25] Ayesha Afzaal , Faria Kanwal , Ayesha Haider Ali , Komal Bashir , and Fatima Anjum. Agent-Based Energy Consumption Scheduling for Smart Grids: An Auction-Theoretic Approach. 13 April 2020, DOI: 10.1109/ACCESS.2020.2987770, IEEE.

[26] Aditya Sundararajan, Alexander S. Hernandez, Arif I. Sarwat. Adapting Big Data Standards, Maturity Models to Smart Grid Distributed Generation: Critical Review. IET Smart Grid, 2020, ISSN 1751-8644.

[27] Sibo Nan, Ming Zhou, Gengyin Li. Optimal residential community demand response scheduling in smart grid. Applied Energy, Volume 210, 15 January 2018, Pages 1280-1289.

[28] Mohammad Tasdighi, Hassan Ghasemi, and Ashkan Rahimi-Kian. Residential Microgrid Scheduling Based on Smart Meters Data and Temperature Dependent Thermal Load Modeling. IEEE Transactions on Smart Grid ( Volume: 5 , Issue: 1 , Jan. 2014 ).

[29] D. Strickland, M.A. Varnosfederani, J. Scott, P. Quintela, A. Duran, R. Bravery, A. Corliss, K. Ashworth, S. Blois-Brooke. A review of community electrical energy systems. Proceedings of the IEEE International Conference on Renewable Energy Research and Applications, IEEE (2016), pp. 49-54.

[30] Luc F.M. van Summeren, Anna J. Wieczorek Gunter J.T. Bombaerts Geert P.J. Verbong. Community energy meets smart grids Reviewing goals, structure, and roles in Virtual Power Plants in Ireland, Belgium and the Netherlands. Energy Research \& Social Science Volume 63, May 2020, 101415.

[31] Derek Machalek, Aaron Young, Landen Blackburn, Pratt Rogers, Kody M.Powell. Mine operations as a smart grid resource: Leveraging excess process storage capacity to better enable renewable energy sources. Minerals Engineering Volume 145, 1 January 2020, 106103.

[32] Marie Chan, Daniel Estève, Christophe Escriba, Eric Campo. A review of smart homes—Present state and future challenges. Computer methods and programs in biomedicine 91 (2008) 55-81.

[33] Yi Ren, Dongming Fan, Qiang Feng, Zili Wang, Bo Sun, Dezhen Yang. Agent-based restoration approach for reliability with 
load balancing on smart grids. Applied Energy 249 (2019) 46-57.

[34] D. Kolokotsa et al. A roadmap towards intelligent net zero-and positive-energy buildings. Solar Energy xxx (2010) xxx-xxx. R. Stephen Carr, Julius N. Dalzell, J. Fred Holmes, John M. Hunt. Oregon Graduate Institute of Science and Technology. 198409-14.

[35] Mehdi Ahrarinouri ; Mohammad Rastegar ; Ali Reza Seifi. Multi-Agent Reinforcement Learning for Energy Management in Residential Buildings. IEEE, 28 February 2020, 10.1109/TII.2020.2977104.

[36] Dimitrios Thomas, Olivier Deblecker, Christos S. Ioakimidis. Optimal operation of an energy management system for a gridconnected smart building considering photovoltaics' uncertainty and stochastic electric vehicles' driving schedule. Applied Energy 210 (2018) 1188-1206.

[37] Gungor V.C., Sahin Dilan, Kocak Taskin, Ergut S., Cecati C., Buccella C., Hancke G.P., A survey on smart grid potential applications and communication requirements, IEEE Transactions on Industrial Informatics, vol. 9, no. 1, pp. $28-42$ (2013).

[38] Alfredo Garro, Max Mühlhäuser, Andrea Tundis, Matteo Baldoni, Cristina Baroglio, Federico Bergenti, Paolo Torroni. Intelligent Agents: Multi-Agent Systems. Encyclopedia of Bioinformatics and Computational Biology, Volume 1, 2019, Pages 315-320.

[39] Khadija Tazi, Fouad Mohamed Abbou \& Farid Abdi. Multi-agent system for microgrids: design, optimization and performance. Applied Energy Volume 259, 1 February 2020, 114140.

[40] Xu Xu, Youwei Jia, Yan Xu, Zhao Xu, Songjian Chai, Chun Sing Lai. A Multi-agent Reinforcement Learning based Datadriven Method for Home Energy Management. IEEE, 04 February 2020, 10.1109/TSG.2020.2971427.

[41] Linyun Xiong, Penghan Li, Ziqiang Wang, Jie Wan. Multi-agent based multi objective renewable energy management for diversified community power consumers. Applied Energy Volume 259, 1 February 2020, 114140.

[42] Ibrahim Abaker Targio Hashem, Victor Chang, Nor Badrul Anuar, Kayode Adewole Ibrar Yaqoob, Abdullah Gani, Ejaz Ahmed, Haruna Chiroma. The role of big data in a smart city. International Journal of Information Management 36 (2016) $748-758$.

[43] Fengming Ran, Dian-ce Gao, Xu Zhang, Shuyue Chen. A virtual sensor based self-adjusting control for HVAC fast demand response in commercial buildings towards smart grid applications. Applied Energy Volume 269, 1 July 2020, 115103.

[44] Alberto Fernández-Isabel, Rubén Fuentes-Fernández, Isaac Martín de Diego. Modeling multi-agent systems to simulate sensorbased Smart Roads. Simulation Modelling Practice and Theory Volume 99, February 2020, 101994.

[45] Soo Wan Yen, Stella Morris, Morris A.G. Ezra, Tang Jun Huat. Effect of smart meter data collection frequency in an early detection ofshorter-duration voltage anomalies in smart grids. Electrical Power and Energy Systems 109 (2019) 1-8.

[46] Geerten van de Kaa, Jafar Rezaei, Behnam Taebi, Ibo van de Poel \& Abhilash Kizhakenath. How to Weigh Values in Value Sensitive Design: A Best Worst Method Approach for the Case of Smart Metering. Science and Engineering Ethics volume 26, pages 475-494(2020).

[47] Szewczyk, Robert Osterweil, Eric Polastre, Joseph et al. Habitat monitoring with sensor networks. Center for Embedded Network Sensing, 47 (6), 2004-05-05.

[48] Atefeh Alirezazadeh, Masoud Rashidinejad, Amir Abdollahi, Peyman Afzali, Alireza Bakhshai. A new flexible model for generation scheduling in a smart grid. Energy Volume 191, 15 January 2020, 116438.

[49] Nipendra Kayastha, Dusit Niyato, Ekram Hossain and Zhu Han. Smart grid sensor data collection, communication, and networking: a tutorial. 23 July 2012 in Wiley Online Library.

[50] Mohamed Elgamal, Nikolay Korovkin, Akram Elmitwally, Zhe Chen. Robust multi-agent system for efficient online energy management and security enforcement in a grid-connected microgrid with hybrid resources. IET Generation, Transmission \& Distribution, Volume 14, Issue 9, 11 May 2020, p. 1726 - 1737.

[51] Bin Zhou, WentaoLi, KaWingChan, YijiaCao, YonghongKuang, XiLiu, Xiong Wang. Smart home energy management systems: Concept, configurations, and scheduling strategies. Renewable and Sustainable Energy Reviews 61 (2016) 30-40.

[52] Melike Erol-Kantarci, Member, IEEE, and Hussein T. Mouftah, Fellow, IEEE. Energy-Efficient Information and Communication Infrastructures in the Smart Grid: A Survey on Interactions and Open Issues. IEEE Transactions on Industrial Informatics, Vol. 12, No. 1, February 2016. IEEE Communication surveys \& Tutorials, Vol. 17, No. 1, First Quarter 2015.

[53] Murat Kuzlu, Manisa Pipattanasomporn, Saifur Rahman. Communication network requirements for major smart grid applications in HAN, NAN, and WAN. Computer Networks 67 (2014) 74-88.

[54] Saber Talari, Miadreza Shafie-Khah, Pierluigi Siano, Vincenzo Loia, Aurelio Tommasetti and João P. S. Cataloão. A review of smart cities based on the internet of thongs concept. Energies 2017, 10, 421.

\section{Authors' Profiles}

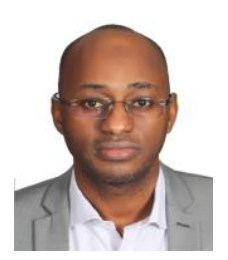

Yazid Hambally Yacouba: Post-graduate student for doctor degree for computer science in Félix Houphouet Boigny University, major in software engineering. 


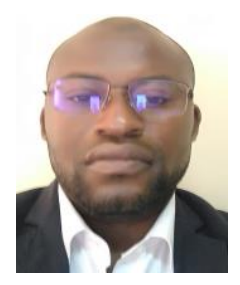

Amadou Diabagaté: Doctor of the school of mathematics and computer science in Félix Houphouet Boigny University, interested in artificial intelligence, data science and big data.

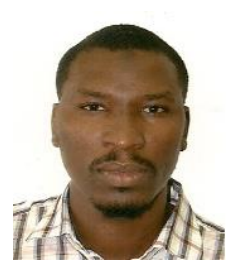

Abdou Maiga: Doctor of the school of mathematics and computer science in Félix Houphouet Boigny University, interested in the smart grid.

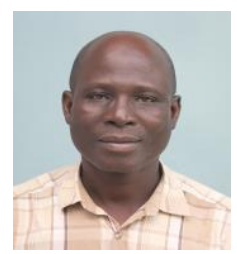

Adama Coulibaly: Lecturer of the school of mathematics and computer science in Félix Houphouet Boigny University interested in the smart grid.

How to cite this paper: Yazid Hambally Yacouba, Amadou Diabagaté, Abdou Maiga, Adama Coulibaly, "Multi-agent System for Management of Data from Electrical Smart Meters", International Journal of Information Technology and Computer Science(IJITCS), Vol.13, No.1, pp.18-43, 2021. DOI: 10.5815/ijitcs.2021.01.02 